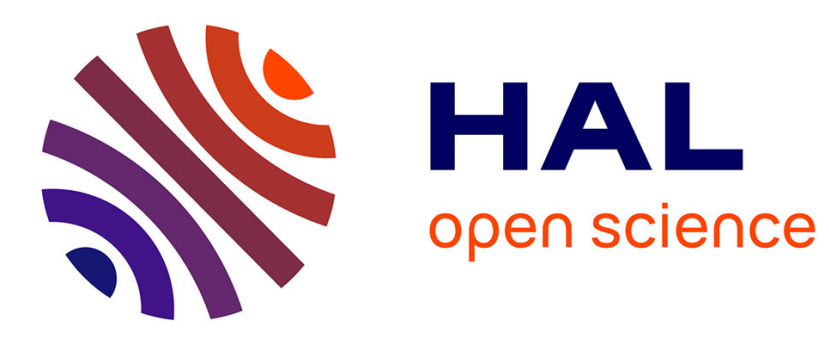

\title{
Nuclear Envelope, Nuclear Lamina, and Inherited Disease
}

Howard J. Worman, Jean-Claude Courvalin

\section{To cite this version:}

Howard J. Worman, Jean-Claude Courvalin. Nuclear Envelope, Nuclear Lamina, and Inherited Disease. International Review of Cytology vol 246, Elsevier, pp.231-279, 2005, 10.1016/S00747696(05)46006-4 . hal-00008858

\section{HAL Id: hal-00008858 https://hal.science/hal-00008858}

Submitted on 22 Sep 2005

HAL is a multi-disciplinary open access archive for the deposit and dissemination of scientific research documents, whether they are published or not. The documents may come from teaching and research institutions in France or abroad, or from public or private research centers.
L'archive ouverte pluridisciplinaire HAL, est destinée au dépôt et à la diffusion de documents scientifiques de niveau recherche, publiés ou non, émanant des établissements d'enseignement et de recherche français ou étrangers, des laboratoires publics ou privés. 


\section{Nuclear Envelope, Nuclear Lamina and Inherited Disease}

Howard J. Worman ${ }^{1}$ and Jean-Claude Courvalin ${ }^{2}$

${ }^{1}$ Departments of Medicine and of Anatomy and Cell Biology, College of Physicians and Surgeons, Columbia University, New York, NY 10032 USA

${ }^{2}$ Departement de Biologie Cellulaire, Institut Jacques Monod, CNRS, Universites Paris 6 and 7, 75251 Paris cedex 05 France

Running Title: Nuclear Envelope and Inherited Disease

Correspondence:

Howard J. Worman

Department of Medicine

College of Physicians and Surgeons

Columbia University

630 West $168^{\text {th }}$ Street

$10^{\text {th }}$ Floor, Room 508

New York, NY 10032

Telephone: (212) 305-8156

Fax: (212) 305-6443

Email: hjw14@columbia.edu 


\section{Table of Contents}

I. Introduction

II. Nuclear Envelope Structure, Function and Proteins
A. Outer Nuclear Membrane and Perinuclear Space
B. Nuclear Lamina
C. Inner Nuclear Membrane

III. Inherited Diseases Caused by Mutations in Nuclear Envelope Proteins
A. Perinuclear Space: TorsinA
B. Integral Inner Nuclear Membrane Proteins
1. LBR
2. MAN1
3. Emerin
C. A-type Lamins
1. Striated Muscle Diseases
2. Partial Lipodystrophy
3. Peripheral Neuropathy
4. Premature Aging Syndromes
5. Other Disorders Caused by Abnormal Prelamin A Processing

IV. Pathogenic Mechanisms
A. Location of Mutations in A-type Lamins and Effects on Protein Function
B. Cellular Defects Resulting from A-type Lamin Mutations
C. Hypothetical Models of Pathogenesis

V. Concluding Remarks/Future Directions

VI. Acknowledgements

VII. Reference List 


\begin{abstract}
$\underline{\text { Abstract }}$
The nuclear envelope is composed on the nuclear membranes, nuclear lamina and nuclear pore complexes. In recent years, mutations in nuclear envelope proteins have been shown to cause a surprisingly wide array of inherited diseases. While the mutant proteins are generally expressed in most or all differentiated somatic cells, many mutations cause fairly tissue-specific disorders. Perhaps the most dramatic case in mutations in A-type lamins, intermediate filament proteins associated with the inner nuclear membrane. Different mutations in the same lamin proteins have been shown to cause striated muscle diseases, partial lipodystrophy syndromes, a peripheral neuropathy and disorders with features of severe premature aging. In this review, we summarize fundamental aspects of nuclear envelope structure and function, the inherited diseases caused by mutations in lamins and other nuclear envelope proteins and possible pathogenic mechanisms.
\end{abstract}

Key Words: Nuclear envelope, lamin, muscular dystrophy, cardiomyopathy, lipodystrophy, peripheral neuropathy, aging, progeria 


\section{Introduction}

The nuclear envelope separates the cytoplasm from the nucleus in eukaryotic cells. It is composed of the nuclear membranes, nuclear lamina and nuclear pore complexes. It has become a focus of increasing attention over the past decade, initially because of the identification of all the components of the nuclear pore complexes and the elucidation of mechanistic details of nucleocytoplasmic transport. More recently, research on the nuclear envelope has been headed in new directions due to the discoveries that mutations in several of its protein components cause a wide range of inherited diseases. This has resulted in attempts to associate what is known, and even what is not known, about nuclear envelope function with disease phenotypes. We summarize here what is known about nuclear envelope structure and function, the inherited diseases caused by mutations in lamins and other nuclear envelope proteins and possible pathogenic mechanisms.

\section{Nuclear Envelope Structure, Function and Proteins}

The nuclear envelope is composed of the nuclear membranes, nuclear pore complexes and nuclear lamina (Figure 1). The nuclear membranes are divided into three morphologically distinct but interconnected domains: outer, inner and pore. The pore membranes connect the inner and outer nuclear membranes at numerous points and are associated with the nuclear pore complexes. Pore membranes contain unique integral proteins, such as gp210 and POM121 in mammals and POM152 in yeast, which form parts of the nuclear pore complexes (Wozniak et al., 1989,1994; Hallberg et al., 1993). Nuclear pore complexes are composed of multiple copies of approximately 30 to 50 different proteins (Rout et al., 2000; Cronshaw et al., 2002). The structure of the pore complex, its protein composition and its role in nucleocytoplasmic transport has been the topic of several relatively recent reviews (Bednenko et al., 2003; Fahrenkrog and Aebi, 2003; Suntharalingam and Wente, 2003; Cronshaw and Matunis, 2004; Rabut et al., 2004).

\section{A. Outer Nuclear Membrane and Perinuclear Space}

The outer nuclear membrane contains ribosomes on its outer surface and has long been assumed to be identical in protein composition to the rough endoplasmic reticulum membrane, with which it is directly continuous. However, recent data suggest that the outer nuclear membrane contains integral proteins involved in nuclear positioning that are not localized to the bulk endoplasmic reticulum (Starr and Han, 2003). Among outer nuclear membrane proteins involved in nuclear positioning are the products of two genes, nesprin 1 and 2, that encode polypeptides containing spectrin repeat sequences (Zhang et al., 2001, 2005; Young and Kothary, 2005). Spectrin repeats were first identified in large structural proteins, the best characterized being plasma membrane or cytoplasmic proteins as dystrophin and alpha-actinin. The general structure of spectrin repeat-containing proteins is a central domain containing the repeats that are competent for self-association, an amino-terminal actin-binding region composed of two calponin 
homology domains and a carboxyl-terminal region containing a distinct functional domain. The carboxyl-terminal regions function in activities such as a membrane association, intermediate filament binding and microtubule binding. Nesprins have this general structure with a transmembrane segment in their carboxyl-terminal regions. Alternative transcription initiation and RNA splicing generate multiple nesprin isoforms with molecular masses ranging from approximately $50 \mathrm{kDa}$ (nesprin-alpha2) to $800 \mathrm{kDa}$ (nuance). These proteins can laterally diffuse in the endoplasmic reticulum membrane, but while the smaller isoforms are able to reach the inner nuclear membrane, the larger isoforms are excluded from this membrane, likely due to the restricted size of the lateral channels of the nuclear pore complex (Soullam and Worman, 1995). However, the larger nesprin isoforms are enriched in the outer nuclear membrane by interactions of their luninal carboxyl-terminal domains with perinuclear luminal SUN domains of integral inner nuclear membrane proteins such as UNC84 and Matefin in Caenorhabditis elegans and SUN1 and SUN2 in mammals (Malone et al., 1999; Lee et al., 2002; Hodzic et al., 2004; Fridkin et al., 2004) (Figure 1). An example is the spectrin repeatcontaining protein ANC-1 in Caenorhabditis elegans, which contains a perinuclear domain that interacts directly or indirectly with the perinuclear SUN domain of UNC84 (Starr and Han, 2002).

In the cytoplasm, different nesprin isoforms are associated via their carboxylterminal transmembrane segments not only with the nucleus but also with other organelles, in particular the endoplasmic reticulum and mitochondria, and through their amino-terminal domains with the actin cytoskeleton. These interactions are of importance during cellular differentiation, for example during myogenesis when myoblasts fuse into highly organized multinucleated muscle fibers in which precise spatial organization is a prerequisite for function (Zhang et al., 2005). Outer nuclear membrane connections to microtubules are also of physiological importance. ZYG-12 in Caenorhabditis elegans is retained in the outer nuclear membrane by binding to SUN1 in the perinuclear space and to the cytoskeleton by binding dynein and microtubules via its amino-terminal domain (Malone et al., 2003). As a result, ZYG-12 maintains the stable attachment of the centrosome to the nucleus, which is necessary for positioning the nucleus in the cell and pulling the nuclear membrane during prometaphase (Beaudouin et al., 2002; Salina et al., 2002). Similar nuclear membrane and dyneinmicrotubule-centrosome connections occur with Klarsicht proteins in Drosophila photoreceptor nuclei (Patterson et al., 2004), where both these proteins and nuclear lamins are required for nuclear migration in the developing eye. The SUN binding domain of Klarsicht and related proteins has been named the KASH (Klarsicht, Anc-1, Syne-1, homology) domain (Figure 1).

Similar to the outer nuclear membrane, the perinuclear space between the inner and outer nuclear membranes has been considered identical to the continuous endoplasmic reticulum lumen. One could imagine, however, that the composition of the perinuclear space could differ from the bulk endoplasmic reticulum lumen as portions of integral proteins localized to the inner and pore membranes within this luminal region could bind to resident non-membrane proteins (Figure 1). Recent data indeed demonstrate that torsinA, a luminal endoplasmic reticulum protein mutated in DYT1 dystonia (see below), 
concentrates in the perinuclear space by binding to the luminal domain of laminaassociated polypeptide 1 when mutated (Goodchild and Dauer, 2005). Hence, the outer nuclear membrane and perinuclear space appear to be differentiated subdomains of the rough endoplasmic reticulum membrane and lumen.

\section{B. Nuclear Lamina}

Using electron microscopy, Fawcett (1966) first described the nuclear lamina of vertebrate cells as a fibrous structure underlying the inner nuclear membrane. Approximately a decade later, Blobel and colleagues (Aaronson and Blobel, 1975; Dwyer and Blobel, 1976; Gerace et al., 1978) demonstrated that the interphase vertebrate lamina is associated with nuclear pore complexes and composed of three major polypeptides called lamin A, lamin B and lamin C. At around the same time, Franke and colleagues (Scheer et al., 1976) obtained biochemical and morphological evidence that a network of fibrils connects the nuclear pore complexes in amphibian oocytes. Gerace and Blobel (1980) first showed that depolymerization of the nuclear lamina during mitosis in cycling cells correlated with hyperphosphorylation of its major protein components. A decade later, specific mitotic phosphorylation sites associated with lamina disassembly were identified (Heald and McKeon, 1990; Ward and Kirschner, 1990; Peter et al., 1990). In 1986, Aebi et al. (1986) and Goldman et al. (1986) provided morphological and biochemical evidence that the nuclear lamina was an intermediate filament-like structure. That same year, cDNA cloning in the laboratories of Blobel (Fisher et al., 1986) and Kirschner (McKeon et al., 1986) showed that nuclear lamins were members of the intermediate filament protein family.

Like their cytoplasmic intermediate filament counterparts, lamins contain head and tail domains of variable structure and conserved alpha-helical central rod domains. Members of the intermediate filament protein family polymerize to form filaments approximately $10 \mathrm{~nm}$ in diameter (Herrmann and Aebi, 2004). The basic building block is the coiled-coiled dimer, which polymerizes to form the higher ordered macromolecular structures. Although all of the different mammalian lamin proteins interact in the yeast two-hybrid assay and in vitro (Ye and Worman, 1995; Schirmer and Gerace, 2004), it is not clear whether heteropolymers or only homopolymers of lamins form filaments in vivo and, if so, at what stoichiometries. It is also unclear if lamins in mammalian somatic cell nuclei polymerize between the inner nuclear membrane and chromatin by the same mechanism as intermediate filament proteins polymerize in the cytoplasm to form $10 \mathrm{~nm}$ diameter filaments.

In contrast to vertebrate cytoplasmic intermediate filament proteins, nuclear lamins contain an additional 42 amino acids in their rod domains. They also have nuclear localization signals in their tail domains. Except for lamin C, lamins contain CAAX boxes and are prenylated, specifically farnesylated, either permanently or transiently at their carboxyl termini (Beck et al., 1988,1990; Wolda and Glomset, 1988; Farnsworth et al., 1989; Weber et al., 1989; Sinensky et al., 1994) (Figure 2). The terminal three amino acids of the CAAX box are cleaved by a protease during the prenylation process (Figure 2). Lamin A is synthesized as a precursor, prelamin $A$, which is farnesylated and then proteolytically processed twice, resulting in the removal of 18 carboxyl-terminal 
amino acids (Sinensky et al., 1994) (Figure 2). Lamins also contain an S-type immunoglobulin fold in their tail domains (Dhe-Paganon et al., 2002; Krimm et al., 2002).

Lamins have been identified in numerous eukaryotic species, including the model invertebrate organisms Drosophila melanogaster (Fisher et al., 1982; Lin and Fisher, 1990; Riemer and Weber, 1994) and Caenorhabditis elegans (Riemer et al., 1993). However, lamin gene orthologues do not appear to be present in budding or fission yeast genomes. Lamins have also been extensively characterized in Xenopus laevis (Krohne et al., 1984, 1987; Stick, 1988, 1992, 1994; Doring and Stick, 1990). In humans, three genes encode nuclear lamins (Biamonti et al., 1992; Lin and Worman, 1993, 1995) (Figure 2). LMNA is localized on chromosome 1q21.2 (Wynder et al., 1996), LMNB1 is on chromosome 5q23.3-q31.1 (Wydner et al., 1996) and LMNB2 on chromosome 19p13.3 (Biamonti et al., 1992). Orthologous genes at syntenic chromosomal locations are present in mice. LMNA encodes the A-type lamins. Lamins $\mathrm{A}$ and $\mathrm{C}$ arise by alternative splicing of RNA encoded by $L M N A$ (Fisher et al., 1986; McKeon et al., 1986; Lin and Worman, 1993) (Figure 2). These proteins are identical for their first 566 amino acids and vary in their carboxyl terminal tails. Lamin A $\Delta 10$, an isoform lacking the amino acids encoded by exon 10 , is also generated by alternative RNA splicing (Machiels et al., 1996). Lamins $A$ and $C$ and possibly lamin $A \Delta 10$ are expressed in most somatic cells but are absent from or expressed in diminished quantities in early embryos, some hematopoietic cells, some types of neuron, most undifferentiated epithelial and mesenchymal cells, and several types of cancer (Guilly et al., 1987, 1990; Lebel et al., 1987; Stewart and Burke, 1987; Worman et al., 1988; Rober et al., 1989, 1990; Cance et al., 1992). Lamin C2, a germ cell-specific, arises from alternative splicing of RNA encoded by an alternative first exon of $\angle M N A$ (Furukawa et al., 1994; Alsheimer and Benavente, 1996). Two genes encode B-type lamins. $L M N B 1$ encodes lamin $B 1$, which seems to be expressed in all somatic cells (Lin and Worman, 1995). LMNB2 encodes lamin B2, which is expressed in all or most somatic cells (Höger et al., 1990), and lamin B3, a germ cell-specific (Furukawa and Hotta, 1993).

Since its discovery, the nuclear lamina has been thought to play primarily a structural role, supporting the nuclear membranes and the nuclear pore complexes. This putative role was suggested by the filamentous structure of the lamina and the fact that its protein building blocks are intermediate filament proteins. Mouse cells lacking lamin B1 have severely abnormal nuclear morphology (Vergnes et al., 2004). Although some vertebrate somatic cells do not express A-type lamins, cells that normally contain them have abnormalities in nuclear architecture and the mislocalization of integral proteins of the inner nuclear membrane when they are absent (Sullivan et al., 1999; Harborth et al., 2001; Muchir et al., 2003; Nikolova et al., 2004). Such cells also have increased nuclear deformability, decreased mechanical stiffness and decreased viability when subjected to mechanical strain (Broers et al., 2004; Lammerding et al., 2004). Numerous fairly recent studies have also shown that cells expressing mutant A-type lamins have abnormalities in nuclear morphology (Östlund et al., 2001; Raharjo et al., 2001; Vigouroux et al., 2001; Novelli et al., 2002; Bechert et al., 2003; Capanni et al., 
2003; Chen et al., 2003; De Sandre-Giovannoli et al., 2003; Eriksson et al., 2003; Favreau et al., 2003; Holt et al., 2003; Mounkes et al., 2003; Csoka et al., 2004a; Goldman et al., 2004; Muchir et al., 2004; Navarro et al., 2004; Reichart et al., 2004, Scaffidi and Misteli, 2005). In addition, cells with certain lamin A/C mutants have increased susceptibility to damge from heat shock (Vigouroux et al., 2001). The lamina also plays a role in anchoring or positioning the nuclear pore complexes, based on their co-purification in a "pore complex-lamina fraction" (Dwyer and Blobel, 1974; Aaronson and Blobel, 1975) and its interaction with Nup153 (Smythe et al., 2000; Hawryluk-Gara et al., 2005). Nuclear lamins may also be involved in the biogenesis or maintenance of the nuclear envelope membranes, as over-expression of prenylated lamins in cells induces excessive nuclear membrane formation and growth (Ralle et al., 2004; Prufert et al., 2004).

Based on its location at the inner nuclear membrane, the lamina has long been thought to anchor chromatin to the nuclear envelope (Figure 1). The binding of lamins to whole chromatin, DNA and histones supports such a function (Luderus et al., 1992, 1994; Glass et al., 1993; Taniura et al., 1995; Goldberg et al., 1999; Stierlé et al., 2003). Lamins have also been implicated in RNA polymerase II-dependent transcription (Kumaran et al., 2002; Spann et al., 2002) and control of DNA replication (Meier et al., 1991; Spann et al., 1997; Moir et al., 2000a). However, the precise spatial coincidence between the intranuclear pool of A-type lamins and DNA replication sites is a matter of debate (Kennedy et al., 2000; Dimitrova and Berezney, 2002; Barbie et al., 2004). Some studies have also implicated lamins in RNA splicing (Jagatheesan et al., 1999; Kumaran et al., 2002) but recent evidence indicates that formation of nuclear splicing compartments is independent of lamins A and C (Vecerova et al., 2004). Since lamins or domains of lamins have not been directly studied in in vitro assays of DNA replication, transcription and RNA splicing, their roles in these processes may be indirect, resulting from secondary effects of the pleiotropic functions of lamins. The discoveries described below that mutations lamins $A$ and $C$ cause several different tissue-specific diseases have revealed that the lamina likely plays an important role in the regulation of gene expression, development of certain cell lineages and possibly other critical cellular processes.

\section{Inner Nuclear Membrane}

The lamina interacts with integral proteins of the inner nuclear membrane. A proteomics analysis has suggested that as many as 80 transmembrane proteins are localized to the inner nuclear membrane in mammalian interphase cells (Schirmer et al., 2003). To date, only approximately a dozen of these proteins have been characterized in detail. Most integral proteins of the inner nuclear membrane have amino-terminal domains that face the nucleoplasm and either single or multiple transmembrane segments. These proteins are synthesized on the rough endoplasmic reticulum membrane and diffuse laterally to reach the inner nuclear membrane, where interactions with the lamina, the chromatin or both retain them (Soullam and Worman, 1993, 1995; Ellenberg et al., 1997; Östlund et al., 1999; Wu et al., 2002). Size constraints imposed by the lateral channels of the nuclear pore complex appear to restrict proteins with 
nucleocytoplasmic domains of larger than approximately $60 \mathrm{kDa}$ from reaching the inner nuclear membrane (Soullam and Worman, 1995; Wu et al., 2002). In addition, energydependent remodeling of pore complexes may be necessary to allow integral proteins to diffuse through the pore membranes (Ohba et al., 2004).

During mitosis, integral inner nuclear membrane proteins dissociate from the lamina and chromatin and are dispersed into a residual endoplasmic reticulum; they subsequently diffuse in this membrane structure back to decondensing chromatin to reform nuclear envelopes in the daughter cells (Ellenberg et al., 1997; Yang et al., 1997). Like lamins, inner nuclear membrane proteins are phosphorylated on specific sites concurrent with mitotic nuclear envelope disassembly (Courvalin et al., 1992; Foisner and Gerace, 1993; Ellis et al., 1998). Several integral inner nuclear membrane proteins are targeted to decondensing chromatin early in nuclear reassembly, prior to the assembly of the lamina, likely via their interactions with chromatin components (Chaudhary and Courvalin, 1993; Buendia and Courvalin, 1997; Haraguchi et al., 2000). Specific integral proteins of the inner nuclear that have been shown to cause human diseases when mutated are discussed in detail below.

\section{Inherited Diseases Caused by Mutations in Nuclear Envelope Proteins}

Research on the nuclear envelope took a turn in a new direction in 1994 when the gene mutated in X-linked Emery-Dreifuss muscular dystrophy was identified (Bione et al., 1994). Soon after this discovery, the encoded protein, called emerin, was shown to be an integral inner nuclear membrane protein (Manilal et al., 1996; Nagano et al., 1996). Then, in 1999, mutations in lamins $A$ and $C$ were reported to cause the autosomal dominantly inherited form of Emery-Dreifuss muscular dystrophy (Bonne et al., 1999). Between 1999 and 2004, mutations in A-type lamins were surprisingly shown to cause several other inherited disorders, some affecting striated muscles but others with dramatically different phenotypes. In the past few years, disease-causing mutations have additionally been identified in the protease responsible for prelamin $A$ processing, two other integral proteins of the inner nuclear membrane and an endoplasmic reticulum protein that abnormally concentrates in the perinuclear space when mutated. Despite our gaps in understanding many of their fundamental functions, much of the current research on the nuclear envelope is focused on how mutations in its protein components cause inherited diseases.

\section{A. Perinuclear Space: TorsinA}

Dystonia refers to a condition characterized by involuntary, sustained muscle contractions affecting one or more sites of the body. The term torsion describes the twisting nature of body movements observed in subjects with dystonia. Several types of primary inherited torsion dystonias can be distinguished based on their clinical features and genetics (Fahn, 1991). In 1997, Ozelius et al. (1997a, 1997b) mapped the locus for an early-onset autosomal dominant dystonia to chromosome $9 \mathrm{q} 34$ and demonstrated mutation in the DYT1 gene encoding an ATPase they called torsinA. Most cases had a 
three base pair deletion in the gene that resulted in loss of one of a pair of glutamate residues.

TorsinA is normally localized to the lumen of the endoplasmic reticulum. In 2004, Goodchild and Dauer (2004) and subsequently other groups (Gonzalez-Alegre and Paulson, 2004; Naismith et al., 2004) reported that the disease-causing torsinA mutant is concentrated in the perinuclear space as opposed to the bulk endoplasmic reticulum. Goodchild and Dauer (2005) have recently shown that the disease-causing mutant binds preferentially to the luminal domain of lamina-associated polypeptide 1, an integral protein of the inner nuclear membrane (Senior and Gerace, 1988), while wild type torsinA preferentially binds to a related integral protein of the bulk endoplasmic reticulum membrane.

It is not known how mislocalization of torsinA to the perinuclear spaces leads to damage or death of particular types of neurons. One hypothesis is that it interferes with connections between integral proteins of the inner and outer nuclear membranes that occur within the perinuclear space (Gerace, 2004). Mislocalized torsinA may interfere with these protein-protein interactions (see above), altering proper anchoring of the nucleus to the cytoskeleton. This intriguing hypothesis remains to be tested as a pathogenic mechanism in DYT1 dystonia.

Mutant torsinA has been studied in vertebrate and invertebrate animal models. Transgenic mice overexpressing human mutant torsin $\mathrm{A}$ in neurons develop abnormal involuntary dystonic-appearing movements as early as three weeks after birth (Shashidharan et al., 2005). The animals also have hyperkinesias and rapid bidirectional circling. Transgenic mutant torsinA is localized to the nuclear envelope, sometimes in perinuclear inclusions and aggregates (Goodchild and Dauer, 2004; Shashidharan et al., 2005). In Drosophila, expression of mutant human torsinA elicits locomotor defects and induces morphological defects at the neuromuscular junctions, some of which resemble those reported in mutants with defects in transforming growth factor-beta signaling (Koh et al., 2004). Null mutations in the Caenorhabditis elegans torsinA homologue ooc-5 result in defects in spindle orientation, nuclear rotation and polarity in early embryos (Basham and Rose, 1999, 2001). These animal models suggest possible connections between torsinA, nuclear positioning and possibly transforming growth factor-beta signaling.

\section{B. Integral Inner Nuclear Membrane Proteins 1. $L B R$}

LBR was first identified as a relatively abundant protein in avian erythrocyte nuclear envelopes that bound to B-type lamins, hence its being named lamin $B$ receptor (Worman et al., 1998). Complementary DNA cloning and sequencing has shown that LBR has a basic, amino-terminal domain of approximately 200 amino acids that faces the nucleoplasm followed by a mostly hydrophobic domain with eight putative transmembrane segments (Worman et al., 1990; Ye and Worman, 1994). The human $L B R$ gene contains 13 protein-coding exons and is located on chromosome 1q42.1 (Schuler et al., 1994; Wydner et al., 1996). 
The nucleoplasmic domain of LBR interacts with B-type lamins (Worman et al., 1988; Ye and Worman, 1994), orthologues of Drosophila heterochromatin protein 1 (Ye and Worman, 1996; Ye et al., 1997) and DNA (Ye and Worman, 1994; Duband-Goulet and Courvalin, 2000). Its hydrophobic domain has a high degree of sequence similarity to sterol reductases of the endoplasmic reticulum that are conserved in plants, yeast and animals (Schuler et al., 1994; Holmer et al., 1998). Human LBR has C14-sterol reductase activity when expressed in yeast (Silve et al., 1998). These finding have led to the hypothesis that LBR is a "bi-functional" protein involved in nuclear organization and sterol metabolism. This indeed appears to be the case based on more recent findings in human disorders.

Pelger-Huët anomaly is an autosomal dominantly inherited condition in which the normally hyperlobulated nuclei of peripheral blood granulocytes have two as opposed to the usual five or more lobes that contain coarser and denser heterochromatin (Pelger, 1928; Huët, 1932; Klein et al., 1955). Hoffmann et al. (2002) used positional cloning to show that mutations in the $L B R$ gene cause this disorder. This has been confirmed in additional subjects (Best et al., 2003). Homozygosity for Pelger-Huët anomaly has been associated with skeletal abnormalities and early lethality (Aznar and Vaya, 1981). Waterham et al. (2003) identified a homozygous $L B R$ mutation in a human fetus that died in utero with Greenberg/HEM skeletal dysplasia. This is a rare, lethal disorder characterized by skeletal dysplasia, severe hydrops, short-limbed dwarfism and marked disorganization of cartilage and bone calcification with a moth-eaten aspect (Greenberg et al., 1988). Waterham et al. (2003) also found elevated levels of cholesta-8,14-dien-3beta-ol in cultured skin fibroblasts of their subject, compatible with a deficiency of the cholesterol biosynthetic enzyme 3-beta-hydroxysterol delta(14)-reductase. Hence, the human clinical syndromes associated with heterozygous and homozygous mutations in $L B R$ are consistent with its known associations with chromatin and the lamina and its sequence similarity to other sterol reductases. It appears that having only one copy of wild type $L B R$ is compatible with life but leads to a morphological nuclear abnormality only in a particular type of cell with nuclei of a highly specialized shape. On the other hand, loss or mutation of both copies of $L B R$ appears to be incompatible with long-term human life but it is not clear if lethality is due to deficiency in a critical sterol reductase activity during fetal development or abnormalities in gene expression that occur as a result of more profound alterations in chromatin organization.

In mice, ichthyosis mutants have mutations in $\mathrm{Lbr}$ (Shultz et al., 2003). These mice have a blood granulocyte phenotype similar to human Pelger-Huët anomaly but homozygous mutants survive and develop other phenotypic abnormalities, including alopecia, variable expression of syndactyly and hydrocephalus. Inherited Pelger-Huët anomaly has also been reported to occur in rabbits, cats and several breeds of dogs but mutations genetic mutations have not yet been described in these species. Depletion of the Drosophila orthologue of LBR by RNA interference in embryos and cultured cells induces no obvious effect on viability or nuclear architecture (Wagner et al., 2004).

\section{MAN1}

The "MAN antigens" were originally identified as three nuclear envelope proteins 
recognized by autoantibodies from a human subject with a collagen vascular disease (Paulin-Levasseur et al.,1996). One of the "MAN antigens" was identified as lamina associated polypeptide 2-beta (Lang et al., 1999). This is an integral protein of the inner nuclear membrane with a single transmembrane segment and nucleoplasmic aminoterminal domain that associates with the lamina and chromatin (Foisner and Gerace, 1993). Lin et al. (2000) used expression cloning to show that the largest of the "MAN antigens," MAN1, is a protein of approximately $97 \mathrm{kDa}$, with a nucleoplasmic aminoterminal domain, two transmembrane segments and a nucleoplasmic carboxyl-terminal domain encoded by a human gene on chromosome 12q14. Sequence analysis showed that MAN1 shares a conserved globular motif of approximately 40 to 50 amino acids near it amino-terminus, termed the LEM domain, with lamina-associated polypeptide 2 and emerin (Lin et al., 2000). It is composed mostly of two large alpha helices and binds to the nucleoplasmic protein barrier-to-autointegration factor (Cai et al., 2001; Laguri et al,, 2001; Wolff et al., 2001). The LEM domain has since been found in several other mammalian integral proteins of the inner nuclear membranes and some other nuclear proteins (Schirmer et al., 2003).

Recent work from several laboratories has shown that the carboxyl-terminal domain of mammalian MAN1 and its Xenopus orthologues binds to Smad1, Smad2 and Smad3 and antagonize signaling by bone morphogenic protein and transforming growth factor-beta (Osada et al., 2003; Raju et al., 2003; Hellemans et al., 2004; Lin et al., 2005; Pan et al., 2005). Using positional cloning, Hellemans et al. (2004) showed that osteopoikilosis, Buschke-Ollendorff syndrome and melorheostosis are allelic variants caused by loss-of-function mutations in MAN1. Fibroblasts from subjects with these disorders also showed enhanced expression of transforming growth factor-beta responsive genes (Hellemans et al., 2004). Osteopoikilosis is an autosomal dominant skeletal dysplasia characterized by multiple areas of hyperostotic bone and can occur either as an isolated anomaly or in association with other bone and skin abnormalities (Berlin et al., 1967; Chigira et al., 1991). Buschke-Ollendorff syndrome is the association of osteopoikilosis with disseminated connective-tissue nevi (Buschke and Ollendorff, 1928; Giro et al., 1992). Melorheostosis is characterized by hyperostosis of tubular bone cortex and frequently accompanied by abnormalities of adjacent soft tissues, such as joint contractures, sclerodermatous skin lesions, muscle atrophy and hemangiomas (Campbell et al., 1969; Rozencwaig et al., 1997). Enhanced bone morphogenic protein and transforming growth factor-beta signaling can explain most or all of the phenotypes in these allelic disorders caused by MAN1 mutations.

The phenotype of Man1 null mice has not yet been reported. Interference with endogenous MAN1 function in Xenopus laevis using antisense morpholino oligonucleotides leads to the reduction of anterior neuroectoderm, consistent with enhanced bone morphogenic protein signaling (Osada et al., 2003). In Caenorhabditis elegans, RNA interference-mediated removal of approximately $90 \%$ of the MAN1 orthologue is lethal in approximately $15 \%$ of embryos but those surviving develop into normal fertile adults (Liu et al., 2003). In the absence of the emerin orthologue, approximately $90 \%$ reduction of MAN1 in Caenorhabditis elegans is lethal to all embryos by the 100-cell stage, with a phenotype involving repeated cycles of anaphase 
chromosome bridging and cytokinesis (Liu et al., 2003).

\section{Emerin}

Emery and Dreifuss (1966) described a X-linked form of muscular dystrophy with early contractures of the elbows, Achilles tendons and postcervical muscles, slowly progressive muscle wasting and weakness with a humeroperoneal distribution and cardiomyopathy usually presenting as heart block. Rowland et al. (1979) subsequently proposed the term Emery-Dreifuss muscular dystrophy for this condition. In 1994, using positional cloning, Toniolo and associates (Bione et al., 1994) identified a gene on the $X$ chromosome encoding a 254 amino acid protein they named emerin, in honor of Professor Emery, that is mutated in X-linked Emery-Dreifuss muscular dystrophy. Arahata and colleagues (Nagano et al., 1996) and Morris and colleagues (Manilal et al., 1996) subsequently showed that emerin was a nuclear envelope protein lacking from most subjects with X-linked Emery-Dreifuss muscular dystrophy. Sequences in the nucleoplasmic domain of wild type emerin mediate its inner nuclear membrane retention (Östlund et al., 1999; Tsuchiya et al., 1999).

Emerin has a nucleoplasmic amino-terminal domain of 220 amino acids, a single transmembrane segment and a short luminal tail in the perinuclear space. It contains a LEM domain near its amino-terminus (Lin et al., 2000; Wolff et al., 2001). The nucleoplasmic domain of emerin binds to lamins A and C (Fairley et al., 1999; Sullivan et al., 1999; Clements et al., 2000; Sakaki et al., 2001). It also binds to chromatinassociated proteins such as barrier-to-autointegration factor, via its LEM domain, the transcription factor germ cell-less (Lee et al., 2001; Holaska et al., 2003) and Btf, a death promoting transcriptional repressor (Haraguchi et al., 2004). Emerin has also been implicated in capping the pointed ends of actin filaments in the nucleus (Holaska et al., 2004). Despite receiving considerable attention, the physiological significance of these protein-protein interactions and their consequences for disease pathogenesis in cells lacking emerin remain unclear.

In most cases, skeletal and cardiac muscle from patients with X-linked EmeryDreifuss muscular dystrophy shows a deficiency or a complete lack of emerin (Manilal et al., 1996; Nagano et al., 1996; Ellis et al., 2000; Sewry, 2000; Niebroj-Dobosz et al., 2003). Analysis of cultured fibroblasts from affected subjects or ectopic expression of mutant emerin have emphasized the weakening of the interactions between emerin and A-type lamins (Clements et al., 2000; Ellis et al., 1999; Fairley et al., 1999) that can provoke an increase in the solubility of all lamin types (Markiewicz et al, 2002). However, the spatial chromosome organization studied in the cells of an individual with the X-linked Emery-Dreifuss muscular dystrophy using chromosome painting was not altered (Boyle et al., 2001). Thus, there has been no emergence of a clear model that would explain the pathophysiology of X-linked Emery-Dreifuss muscular dystrophy. Owing to the specific interactions of emerin with A-type lamins, a similar mechanism may be operating for X-linked and autosomal forms of the disease (see below).

The phenotype of emerin-deficient mice has not yet been reported. In Caenorhabditis elegans, depletion of the emerin orthologue using RNA interference leads to no detectable phenotype throughout development (Gruenbaum et al.. 2002). 
Depletion of both the emerin and MAN1 orthologues in Caenorhabditis elegans is lethal (Liu et al., 2003).

\section{A-type Lamins}

1. Striated Muscle Diseases

Emery-Dreifuss muscular dystrophy is also inherited as an autosomal dominant disorder, which is clinically identical to the X-linked form (Fenichel et al., 1982; Miller et al., 1985; Emery, 1989). Bonne et al. (1999) mapped the locus for autosomal dominant Emery-Dreifuss muscular dystrophy to chromosome 1q11-q23 and showed that mutations in $\angle M N A$ co-segregated with the disease phenotype. These results were the first identification of mutations in A-type nuclear lamins as a cause of an inherited disorder. Subsequently, Fatkin et al. (1999) showed that lamin A/C mutations cause a dilated cardiomyopathy with conduction defect, a condition in which the affected subjects have heart abnormalities identical to those in subjects with Emery-Dreifuss muscular dystrophy but minimal or no skeletal muscle involvement. The following year, Muchir et al. (2000) reported A-type lamin mutations cause autosomal dominant limb girdle muscular dystrophy type $1 \mathrm{~B}$, which also has the same cardiac abnormalities but a different distribution of skeletal muscle involvement. Analyses of additional families showed that these allelic variants could occur in different subjects with the same mutation even within the same family (Bonne et al., 2000; Brodsky et al., 2000). Other atypical patterns of muscle involvement have also been described, as well as significant atypical variability in different subjects with the same mutation (Forissier et al., 2003; Sebillon et al., 2003; Mecuri et al., 2004). Rare LMNA compound heterozygotes have also been identified in which Emery-Dreifuss muscular dystrophy is inherited in an autosomal recessive manner (Raffaele Di Barletta et al., 2000). The emerging picture is that certain mutations in A-type lamins cause striated muscle disease characterized by a predominant cardiomyopathy with skeletal muscle either affected in an EmeryDreifuss pattern, a limb girdle distribution, an atypical pattern or not at all. From a clinical perspective, the cardiomyopathy is the life-threatening component of these disorders caused by LMNA mutations (Sanna et al., 2003; Taylor et al., 2003; van Berlo et al., 2005).

Mutations in $\angle M N A$ that cause striated muscle disease are found throughout most of the coding region for lamins $A$ and $C$ (Figure 3 ). Most are either amino acids substitutions or single amino acid deletions. Some splicing mutations have been identified, as have nonsense mutations early in the coding sequence that result in essential haploinsufficient for lamins $A$ and $C$. Based on one report of neonatal lethality (van Engelen et al., 2005) and the lack of reports of surviving adults, homozygosity for a single $L M N A$ mutation that causes striated muscle disease appears to be incompatible with postnatal human life.

The generation of Lmna null mice by Sullivan et al. (1999) has provided an informative animal model of Emery-Dreifuss muscular dystrophy. Soon after birth, homozygous $L m n a$ null mice show a reduction in their growth rate and develop a cardiac and skeletal myopathy bearing a striking resemblance to the human disease. The cardiac condition is a rapidly progressing dilated cardiomyopathy without 
compensatory hypertrophy (Nikolova et al., 2004). More recently, Arimura et al. (2005) have generated "knockin" mice carrying a Lmna H222P mutation. At adulthood, homozygous mice display reduced locomotion activity with a stiff walking posture, cardiac chamber dilation and hypokinesia with conduction defects. In contrast to affected humans, however, mice with one normal copy of Lmna are apparently normal.

\section{Partial Lipodystrophy}

Lipodystrophies are a heterogeneous group of syndromes characterized by a paucity of adipose tissue often associated with insulin-resistant diabetes mellitus (Reitman et al., 2000). Dunnigan-type familial partial lipodystrophy, also known as lipoatrophic diabetes mellitus and Dunnigan-Köbberling syndrome, is an autosomal dominant disorder characterized by peripheral fat loss, excess central adiposity, insulin resistance and usually type II diabetes mellitus (Dunnigan et al., 1974; Köbberling et al., 1975; Jackson et al., 1997). Some affected subjects have generalized hypertrophy of skeletal muscles (Wildermuth et al. 1996; Vantyghem et al., 2004). In 1998, the gene for Dunnigan-type partial lipodystrophy was mapped to chromosome 1q21-22 (Jackson et al., 1998; Peters et al., 1998). This chromosome region contains $L M N A$ and subsequently mutations in lamins $\mathrm{A}$ and $\mathrm{C}$ were identified in affected subjects (Cao and Hegele, 2000; Shackleton et al., 2000; Speckman et al., 2000).

Approximately $90 \%$ of the mutations that cause Dunnigan-type partial lipodystrophy are localized in exon 8 of $L M N A$, in particular at codons 482 and 486 (Cao and Hegele, 2000; Shackleton et al., 2000; Speckman et al., 2000; Vigouroux et al., 2000; Garg et al., 2001) (Figure 3). Mutations in exon 11 of $L M N A$ at codons 582 and 584 occur in some atypical cases of Dunnigan-type partial lipodystrophy (Speckman et al., 2000; Vigouroux et al., 2000; Garg et al., 2001). A heterozygous amino acid substitution at residue 133 of the lamin $A / C$ rod domain has also been described in a subject with generalized lipoatrophy with insulin-resistant diabetes, hypertriglyceridemia, hepatic steatosis, hypertrophic cardiomyopathy with valvular involvement and disseminated whitish papules (Caux et al., 2003). Two families with Dunnigan-type partial lipodystrophy with mutations in the lamin $A / C$ head domain have also been described that have cardiac conduction system defects and cardiomyopathy (Garg et al., 2002).

Mandibuloacral dysplasia is a rare autosomal recessive disorder, characterized by postnatal growth retardation, craniofacial anomalies, skeletal malformations, mottled cutaneous pigmentation and progeroid features (Young et al., 1971; Zina et al., 1981; Pallotta and Morgese, 1984). In addition, affected individuals have prominent partial lipodystrophy, insulin resistance and diabetes mellitus (Cutler et al., 1991; Freidenberg et al., 1992). Fat loss patterns in mandibuloacral dysplasia has been classified as type A, with loss of subcutaneous fat from the extremities but normal or excess fat in the neck and truncal regions, and type $B$, with generalized loss of subcutaneous fat involving the face, trunk and extremities (Simha and Garg, 2002). Since individuals with mandibuloacral dysplasia have partial lipodystrophy, Novelli et al., (2002) hypothesized that the disease may be caused by mutations in the $L M N A$ gene. They analyzed five consanguineous families and demonstrated linkage to chromosome 1q21 and identified a homozygous missense mutation at amino acid residue 527 of lamin A/C in all of their 
affected subjects (Figure 3). The same mutation was subsequently identified in other affected subjects with the type A distribution of fat loss (Shen et al., 2003; Simha et al., 2003).

Although Lmna null mice develop cardiomyopathy and skeletal muscular dystrophy, they do not develop partial lipodystrophy or insulin resistance (Sullivan et al., 1999; Cutler et al., 2002). This strongly suggests that partial lipodystrophy does not result from loss of lamin A or $\mathrm{C}$ function. Adipocyte loss in lipodystrophies caused by lamin $\mathrm{A} / \mathrm{C}$ mutations may therefore result from dominant interference with a specific laminmediated activity necessary for survival of differentiated adipocytes.

\section{Peripheral Neuropathy}

Charcot-Marie-Tooth disorders are a group of clinically and genetically heterogeneous hereditary motor and sensory neuropathies, mainly characterized by muscle weakness and wasting, and foot deformities and characteristic electrophysiological and histological changes (Saifi et al., 2003). Type 2 Charcot-MarieTooth disorders are defined by a slight or absent reduction of nerve conduction velocities, loss of large myelinated fibers and axonal degeneration. De SandreGiovannoli et al. (2002), using homozygosity mapping in inbred Algerian families, provided evidence for linkage of an autosomal recessive Charcot-Marie-Tooth type 2 disorder to chromosome 1q21.2-q21.3. They then showed that all affected subjects in these families as well as additional subjects in an unrelated family shared a common homozygous mutation in $L M N A$ that led to an amino acid substitution at residue 298 in the lamin $A / C$ rod domain (Figure 3 ). Subsequent analysis of 21 subjects from seven unrelated Algerian families with the same lamin $A / C$ mutation showed marked variability of the clinical phenotype (Tazir et al., 2004). There is a wide range of age of onset, from six to 27 years, with a mean of 14.4 years. Some affected individuals with disease duration of ten to 15 years had a severe phenotype with distal wasting and weakness of all four limbs and areflexia associated with involvement of the proximal lower limb muscles. Others had a more classical Charcot-Marie-Tooth phenotype with mild functional disability without proximal lower limb involvement after five to 18 years. Electrophysiological studies showed a median motor nerve conduction velocity in the normal range in almost all the subjects and nerve biopsies in six patients revealed severe rarefaction of myelinated fibers and an increased density of demyelinated fibers.

Individuals with Charcot-Marie-Tooth disorders do not typically develop a primary muscular dystrophy or cardiomyopathy. The specific mutation in the rod domain that causes this disease might therefore lead to loss of only one specific function of lamins $\mathrm{A}$ and $\mathrm{C}$, which is necessary for proper nerve cell axonal structure or function. Lmna null mice develop scoliosis/kyphosis and become hunched, which is evocative of a severe peripheral neuropathy (De Sandre-Giovannoli et al., 2002). This was confirmed by ultrastructural exploration of sciatic nerves that revealed a reduction of axon density, axonal enlargement and the presence of nonmyelinated axons, findings highly similar to those observed in human Charcot-Marie-Tooth type 2 disorders (De Sandre-Giovannoli et al., 2002). Thus Lmna null mice develop both muscular dystrophy and axonal neuropathy. Similarly, Walter et al. (2005) recently identified a human 
mutation in the $5^{\prime}$ region of $\angle M N A$ resulting in the loss of 15 nucleotides including the translation ATG initiator codon that segregates in a previously described family with a clinical phenotype that shared features of both Emery-Dreifuss muscular dystrophy and Charcot-Marie-Tooth type 2.

\section{Premature Aging Syndromes}

Hutchinson-Gilford progeria syndrome is an extremely rare autosomal dominant disorder characterized by striking features of premature aging. Subjects are usually apparently normal at birth but develop signs and symptoms by about a year of age. Prominent signs include the complete or almost complete lack of hair, a disproportionately large head, "pinched" facial features, generalized fat loss, thin skin, incomplete extension at the knees and elbows indicating stiffness of joints and a generally aged appearance (DeBusk, 1972; Brown, 1979). Death from premature coronary artery disease is frequent and may occur in the first decade of life. Hutchinson (1886) was apparently the first to write on this disorder and Gilford (1904) later gave the term progeria to it. DeBusk (1972) may have been the first to call it Hutchinson-Gilford progeria syndrome.

Eriksson et al. (2003) localized the gene causing Hutchinson-Gilford progeria syndrome to chromosome $1 \mathrm{q}$ by observing two cases of uniparental isodisomy and a case with a six-megabase paternal interstitial deletion. They identified a de novo point mutation in exon 11 of $L M N A$ that was identical in 18 of 20 classical cases. The mutation is a cytosine to thymidine transition resulting in a silent glycine to glycine change at codon 608 within exon 11 (Figure 3). They identified one additional case with a guanosine to adenine substitution within the same codon. Simultaneously, De Sandre-Giovannoli et al. (2003) reported the same cytosine to thymidine transition at codon 608 in two other subjects with Hutchinson-Gilford progeria syndrome. Cao and Hegele (2003) confirmed that five cell lines from subjects with a diagnosis of Hutchinson-Gilford progeria syndrome carried the cytosine to thymidine mutation and another the guanosine to adenine substitution. D'Apice et al. (2004) further identified the cytosine to thymidine mutation in three additional families. These LMNA mutations create an abnormal splice donor site that generates a mRNA encoding a protein with 50 amino acids deleted from its carboxyl-terminal domain. The amino acids deleted from the mutant protein are unique to prelamin $A$ and not in lamin $C$. The mutant truncated protein is predicated to contain the CAAX box (CSIM) at its carboxyl-terminus but lack the endoproteolytic cleavage site for conversion to prelamin $A$, hence it likely remain farnesylated in cells.

Different $\angle M N A$ mutations have been described in individuals with atypical progeria syndromes (Figure 3). In four patients with a diagnosis of atypical Werner syndrome, Chen et al. (2003) noted heterozygosity for missense mutations in $L M N A$, specifically at amino acid residues 57, 133 and 140. Csoka et al. (2004a) identified heterozygous mutations in three subjects with diagnoses of "atypical Hutchinson-Gilford progeria syndrome," "severe Werner syndrome" and "Seip syndrome." Plasilova et al. (2004) reported a homozygous lamin A/C mutation in a family with individuals diagnosed with "autosomal recessive Hutchinson-Gilford progeria syndrome," however; 
these individuals may actually have had mandibuloacral dysplasia. Based on the available data, it appears that classical Hutchinson-Gilford progeria syndrome is caused by a cytosine to thymidine, or rarely a guanine to adenine, mutation at codon 608 of LMNA. These mutations lead to expression of a truncated prelamin A. Less common atypical conditions with progeroid features may be caused by other lamin $A / C$ mutations.

A progeroid syndrome has been obtained in "knockin" mice homozygous for a proline to leucine substitution at amino acid 530 of lamin A/C (Mounkes et al., 2003). This mutation causes autosomal dominant Emery-Dreifuss muscular dystrophy in humans (Bonne et al., 1999). Mice are normal at birth but rapidly develop severe growth retardation, dying within four to five weeks. Similarities to human progeria include thinning of the skin, hypoplasia and degeneration of cardiac and skeletal muscle, osteoporosis and abnormal dentition. The mechanism of aging in these mice, which could be either an accelerated cell differentiation with premature death or instability to preserve a state of terminal differentiation, has not been elucidated.

\section{Other Disorders Caused by Abnormal Prelamin A Processing}

As discussed briefly above, prelamin A is processed to lamin A by a series of proteolyic reactions catalyzed by ZMPSTE24 that depend upon protein farnesylation. The steps in prelamin processing are outlined in Figure 4. The first step in prelamin A processing is the addition of farnesyl to the cysteine of the CAAX box at the carboxylterminus, which is catalyzed by farnesyl transferase (Sinensky et al., 1994). The second step is the endoproteolytic removal of the last three amino acids by the ZMPSTE24 metalloproteinase, which recognizes the prenylated prelamin A (Leung et al., 2001). In B-type lamins, this step is catalyzed by RCE1 (Maske et al., 2003). The isoprenylated cysteine is then carboxymethylated, a reaction catalyzed by isoprenylcysteine carboxyl methyltransferase (Sinensky et al., 1994; Bergo et al., 2002). Finally, ZMPSTE24 catalyzes a second proteolytic reaction "upstream" to the prenylated cysteine to yield mature lamin A (Kilic et al., 1997; Corrigan et al., 2005). The LMNA mutation in classical Hutchinson-Gilford progeria syndrome in fact leads to abnormal processing of prelamin A because the "upstream" ZMPSTE24 endoprotease site is lacking from the truncated mutant protein.

In a woman with mandibuloacral dysplasia with a type B pattern of fat loss who did not have a detectable $L M N A$ mutation, Agarwal et al. (2003) identified a compound heterozygous mutation in the gene encoding ZMPSTE24. Navarro et al. (2004) examined explored nine fetuses and newborn children with restrictive dermopathy, also known as tight skin contracture syndrome. This is a rare disorder characterized by intrauterine growth retardation, tight and rigid skin with erosions, prominent superficial vasculature, small mouth, small pinched nose, micrognathia, sparse eyelashes and eyebrows, mineralization defects of the skull, thin dysplastic clavicles, pulmonary hypoplasia, multiple joint contractures and an early neonatal lethal course. They found that two had a heterozygous splicing mutation in $\angle M N A$, resulting in expression of a truncated prelamin $A$ protein lacking amino acids also absent from the truncated protein in Hutchinson-Gilford progeria syndrome. The other seven had a heterozygous 
insertion introducing a premature termination codon in ZMPSTE24. Therefore, it appears that mutations in both A-type lamins and ZMPSTE24 protease cause diseases with phenotypic overlap, such as mandibuloacral dysplasia, Hutchinson-Gilford progeria syndrome and restrictive dermopathy. A neonatal "tight skin" phenotype has been recently reported in a subject with classical Hutchinson-Gilford progeria syndrome and the cytosine to thymidine mutation at codon 608 of $L M N A$ (Sevenants et al., 2005).

Disruption of Zmpste24 in mice causes lack of processing or prelamin A to lamin A (Leung et al., 2001; Bergo et al., 2002; Pendás et al., 2002). These mice have been reported to have several abnormalities, including retarded growth, alopecia, micrognathia, dental abnormalities, osteolytic lesions in bones and osteoporosis. Some of these phenotypic features are similar to those in human subjects with HutchinsonGilford progeria syndrome and mandibuloacral dysplasia. Heterozygosity for Lmnadeficiency ameliorates the abnormal phenotype of these mice (Fong et al., 2004).

\section{Pathogenic Mechanisms of Diseases Caused by Mutations in A-type Lamins}

One of the most challenging issues facing investigators who study the nuclear envelope is how mutations in A-type lamins result in such a wide range of clinical conditions. Despite major advances in identifying mutations in these diseases, little has been achieved in understanding pathogenic mechanisms. However, information gained from the sites of these mutations in the lamin $\mathrm{A}$ and lamin $\mathrm{C}$ molecules and the cellular defects observed in cells expressing mutant A-type lamins have lead to the development of several hypothetical models of pathogenesis that are the focus of current experimental testing.

\section{A. Location of Mutations in A-type Lamins and Effects on Protein Function}

Examination of the locations of disease-causing mutations in the lamin $A$ and lamin $\mathrm{C}$ molecules has provided some clues as to why different mutations result in different disease phenotypes. In contrast to individuals with cardiac and skeletal muscle diseases in whom mutations in $\angle M N A$ are located throughout 11 of the 12 exons that encode lamins $A$ and $C$, most individuals with Dunnigan-type partial lipodystrophy have mutations in exon 8 of $L M N A$, in particular at amino acids 482 and 486 (Figure 3). These amino acids are part of an immunoglobulin-like fold in the carboxyl-terminal tails of lamins A and C. Immunoglobulin folds frequently function in interactions between proteins and in interactions between proteins and nucleic acids.

Information obtained from solving the three-dimensional structure the lamin immunoglobulin-like fold provides insights into to how different mutations in this domain that cause striated muscle disease and those that cause partial lipodystrophy may produce different alterations in protein function (Dhe-Paganon et al., 2002; Krimm et al., 2002). Most of the mutations in the immunoglobulin-like fold in lamins $A$ and $C$ known to cause striated muscle disease occur in conserved hydrophobic residues or in buried conserved polar residues. Thus, mutations that cause muscle diseases appear to destabilize the overall structure of the immunoglobulin-like fold. Striated muscle 
diseases also result from mutations in the rod domain of lamin $\mathrm{A}$ or $\mathrm{C}$ and from all of the frameshift and translation termination mutations described so far. The common effect of mutations in muscle pathology might therefore be destabilization of the entire lamin A and/or lamin $\mathrm{C}$ molecule or lamin dimers. This could lead to a global loss of protein function and possibly a destabilization of lamin filaments, consistent with structural or mechanical abnormalities as the primary cellular defect in disease. On the other hand, mutations in the immunoglobulin-like fold that cause Dunnigan-type partial lipodystrophy occur three positions that are close in space and are solvent accessible. These mutations lead to a reduction in the conserved, positively charged character of a surface site defined by these residues. This change in surface charge would not be expected to disrupt protein structure markedly but might perturb the binding of a specific partner, such as a transcription factor, DNA or other chromatin component necessary for adipocyte-specific gene expression.

The information gained from the elegant structural studies of the lamin immunoglobulin-like fold cannot however explain the differences between all mutations reported to cause striated muscle diseases and lipodystrophy (Figure 3). A few of the mutations causing atypical cases of Dunnigan-type partial lipodystrophy are located in a lamin-A specific region, outside of the immunoglobulin-like fold and near the carboxylterminus of the protein at amino acids 582 and 584. In addition, two mutations have been reported to cause both partial lipodystrophy and cardiac abnormalities in the same subjects and are located near the amino-terminus of the rod domain of lamins $A$ and $C$ (Garg et al., 2002). It is possible that these regions of lamins $A$ and $C$ interact in some way with the immunoglobulin-like fold but this has not been demonstrated. The mutation causing mandibuloacral dysplasia is also located within the immunoglobulinlike fold at amino acid 527 and changes an arginine to a histidine. Two copies of this mutant allele must be inherited for the disease to occur. Intriguingly, inheriting one mutant $L M N A$ allele in which the same arginine is changed to a proline leads to striated muscle disease.

The heterozygous deletions that occur at the carboxyl-terminal end of prelamin A in subjects with Hutchinson-Gilford progeria and restrictive dermopathy could have a double effect on lamin A function. First could be the loss of an amino acid stretch that may have specific interactions. Second, the deletions include the cleavage site for ZMPSTE24 endoprotease that normally trims the several amino acids from prelamin A to generate mature lamin A (Figure 4). Thus, the truncated prelamin A should retain at its carboxyl-terminus a farnesylated and carboxymethylated cysteine residue. The same carboxymethylated and farnesylated cysteine would be retained in wild type prelamin A in subjects with inactivating mutations in ZMPSTE24 endoprotease and normal LMNA alleles (Agarwal et al., 2003; Navarro et al., 2004). Ralle et al. (2004) and Prufert et al. (2004) have shown that the modified CAAX box in B-type lamins is responsible for nuclear membrane growth. Therefore, one can imagine that the abnormal persistence of a similarly modified cysteine residue in truncated or wild type prelamin A could confer to the unprocessed protein a membrane proliferation function. In support of this hypothesis, the nuclear perimeter in cultured cells from subjects with 
Hutchinson-Gilford progeria syndrome has a two-fold increase compared to controls, suggesting that excessive membrane biogenesis occurs (Goldman et al., 2004).

Toxicity of posttranslationally modified but unprocessed prelamin $A$ and truncated prelamin $A$ is strongly suggested by recent studies. Long et al. (2004) have shown that the phenotype in Zmpste24 null mice with a normal content in prelamin A is not observed when these mice are crossed to $L m n a+/$ - mice, reducing the prelamin A content by half. The latter mice are apparently normal, suggesting that prelamin $A$ is toxic and that reducing its level provides protection from disease. A similar effect has been observed in cultured HeLa cells (Gruber et al., 2005). Using RNA interference, these investigators showed that dramatic changes in nuclear morphology and premature cell death induced by knocking down ZMPSTE24 expression was prevented by knockdown of prelamin A 24 hours earlier. These data confirm that unprocessed prelamin $A$ is a cellular toxin. Using fibroblasts from subjects with Hutchinson-Gilford progeria syndrome, Scaffidi and Misteli (2005) have recently shown that introduction of wild type lamin A protein does not rescue cellular morphological abnormalities. However, upon correction of the aberrant splicing event using a modified oligonucleotide targeted to the activated cryptic splice site, fibroblasts assumed a normal nuclear morphology and proper expression of several misregulated genes was established. The results of these studies strongly suggest that unprocessed prelamin $A$ and the truncated prelamin A in classical Hutchinson-Gilford progeria syndrome are cellular poisons and identify a possible target for therapeutic intervention.

\section{B. Cellular Defects Resulting from A-type Lamin Mutations}

Although various abnormalities in nuclear structure in tissues of individuals with mutations in A-type lamins have been reported, their relationship to pathophysiology is unclear. Skeletal muscle from individuals with Emery-Dreifuss muscular dystrophy shows an increase in internal nuclei, with fewer nuclei at the normal location near the periphery of the fibers (Brown et al., 2001; Sewry et al., 2001). However, this is a pathological feature that is common to most muscular dystrophies. There can be an abnormal distribution of heterochromatin in cells from individuals with Emery-Dreifuss muscular dystrophy and lamin A and C mutations but it is not clear whether it is a primary or secondary effect (Sabatelli et al., 2001; Sewry et al., 2001; Fidzianska and Hausmanowa-Petrusewicz, 2003). Nerve biopsies from individuals with CharcotMarie-Tooth disorder type 2 caused by $L M N A$ mutation show a substantial loss of large myelinated fibers and abnormally myelinated axons but their nuclei appear normal (De Sandre-Giovannoli et al., 2002). Studies of affected adipocytes from individuals with Dunnigan-type partial lipodystrophy or mandibuloacral dysplasia have not been published.

Cultured fibroblasts from subjects with mutations in A-type lamins have proven to be useful tools for analyzing morphological disorders induced by the mutations (Novelli et al., 2002; Bechert et al., 2003; Capanni et al., 2003; Chen et al., 2003; De SandreGiovannoli et al., 2003; Eriksson et al., 2003; Favreau et al., 2003; Holt et al., 2003; Mounkes et al., 2003; Csoka et al., 2004a; Goldman et al., 2004; Muchir et al., 2004; Navarro et al., 2004; Reichart et al., 2004, Scaffidi and Misteli, 2005). Nuclear defects 
in patients affected with diseases other than the progeroid syndromes mainly consist of nuclear herniations that contain A-type lamins and emerin but have a diminished content in nuclear pore complexes and other inner nuclear membrane proteins. Another abnormality that occurs in nuclei of overall normal shape is a polar defect in B-type lamins and other proteins in an area where the lamina network is irregular, sometimes with a honeycomb aspect. Intranuclear aggregates of lamin A have also been observed, most commonly when mutations are in the lamin $A / C$ rod domain. Nuclear abnormalities are generally obsereved in only a minority of fibroblasts from subjects with LMNA mutations and the percentage of affected cells depends upon culture conditions and passage number (Vigouroux et al., 2001; Muchir et al., 2004). Importantly, there is no clear association of a specific cellular phenotype with a particular mutation or with a particular disease (Muchir et al., 2004). Nonetheless, these morphological alterations suggest that the mechanical properties of the nuclear lamina are altered. This has been confirmed by the extensive deformations observed in nuclei when these cells were submitted to heat shock and by the easier chemical extraction of some of their protein components (Vigouroux et al., 2001).

Nuclear abnormalities observed in cultured fibroblasts from subjects with Hutchinson-Gilford progeria syndrome or restrictive dermopathy are sometimes similar to those in cells from subjects with other diseases caused by different lamin A/C mutations (Eriksson et al., 2003; De Sandre-Giovannoli et al., 2003; Goldman et al., 2004, Navarro et al., 2004; Scaffidi and Misteli, 2005). However, some abnormalities appear specific for these diseases, such as a high degree of nuclear lobulation, a large increase in the nuclear perimeter, a thickening of the lamina, a loss of peripheral heterochromatin and clustering of nuclear pore complexes (Goldman et al., 2004). Expression of the truncated prelamin in classical Hutchinson-Gilford progeria in transfected normal cells induces similar changes (Goldman et al., 2004). Mouse embryo fibroblasts from progeroid mice heterozygous for the L530P lamin A/C mutation have morphological abnormalities consistent with the phenotypes observed in fibroblast cell lines from human subjects with autosomal dominantly inherited disorders caused by various $L M N A$ mutations (Mounkes et al., 2003). Specific features of cells from these mice are their short lifespan, which is not associated with telomere shortening, and increased apoptosis. Nuclei in cells from Zmste24 null mice are polylobulated with herniations and similar to nuclei in cells from subjects with progerias (Pendás et al., 2002; Long et al., 2005).

Analysis of cultured fibroblasts from mice and humans that do not express A-type lamins has clearly demonstrated the close association between A-type lamins and emerin and nesprin-alpha2 (Sullivan et al., 1999; Raharjo et al., 2001; Muchir et al., 2004). These two transmembrane proteins of the nuclear envelope are delocalized to the bulk endoplasmic reticulum membrane in cells lacking lamins $A$ and $C$ and relocalized to the inner nuclear membrane after expression of lamin $A$ by transfection. Fibroblasts lacking lamins $A$ and $C$ also have increased nuclear deformability, decreased mechanical stiffness and decreased viability when subjected to mechanical strain (Broers et al., 2004; Lammerding et al., 2004). 
Expression of mutant A-type lamins in transfected cultured cells reproduces many of the nuclear envelope abnormalities observed in cells from human subjects and mutant mice (Raharjo et al., 2001; Östlund et al., 2001; Favreau et al., 2003; Holt et al., 2003; Bechert et al., 2003; Goldman et al., 2004). Alterations in transfected cells appear to be caused by a dominant negative effects of the mutant proteins and not to a decrease in the stability of the mutant lamins (Östlund et al., 2001). Delocalization of emerin to the bulk endoplasmic reticulum membrane has also been observed when several lamin $A$ mutants that cause striated muscle diseases are expressed in transfected cells but not when the most common mutant that causes Dunnigan-type partial lipodystrophy is expressed (Östlund et al., 2001; Raharjo et al., 2001; Holt et al., 2003). Cell types that have a lower content of endogenous emerin and A-type lamins appear to be more sensitive to developing nuclear structural alterations when mutated lamins are expressed (Favreau et al., 2003). Studies of the dynamics of mutant A-type lamins using green fluorescent protein fusions and photobleaching methods have shown that the mobility of a lamin A mutant in Dunnigan-type partial lipodystrophy is indistinguishable from wild type lamin A but that three mutants causing striated muscle disease have increased mobility within the nuclear lamina (Gilchrist et al., 2004). Similar studies using fluorescence loss in photobleaching have revealed increased mobility of lamin A and lamin C mutants found in striated muscle diseases as well as in Dunnigan-type partial lipodystrophy (Broers et al., 2005).

\section{Hypothetical Models of Pathogenesis}

One of the most intriguing issues regarding inherited diseases caused by mutations in nuclear lamins is how mutations in proteins that are expressed in virtually all somatic cells cause different tissue-specific diseases. Although this issue remains to be resolved, as discussed in several previous reviews, investigators in the field appear to have converged on two main hypotheses that will no doubt be the focus of future testing: the "gene expression" hypothesis and the "mechanical stress" hypothesis (Worman and Courvalin, 2000, 2002, 2004; Cohen et al., 2001; Hutchinson et al., 2001; Wilson et al., 2001; Burke and Stewart, 2002; Goldman et al., 2002; Hutchinson and Worman, 2004). Emerging data suggest that aspects of these hypotheses overlap.

The striated muscle phenotype caused by many LMNA mutations suggests that defective lamins $A$ and $C$ increase cellular sensitivity to mechanical stress. The nuclear lamina, inner nuclear membrane and nuclear pore complexes are tightly connected in the nuclear envelope. Through filaments attached to the cytoplasmic aspect of the nuclear pore complex, the lamina could be connected indirectly with cytoplasmic intermediate filaments, such as desmin in muscle cells, and thus with the dystrophindystroglycan complex of the sarcolemma membrane. Mutations in components of the dystrophin-dystroglycan complex are responsible for several muscular dystrophies (Straub and Campbell, 1997; Cohn and Campell, 2000; Dalkilic and Kunkel, 2003). Electron microscopy of Lmna -/- mice cardiomyocytes shows a disruption of the cytoskeletal desmin network and its detachment from the surface of the nuclei (Nikolova et al., 2004). We have discussed above the connection of the lamina via integral inner 
nuclear membrane proteins of the Sun family to integral proteins of the outer nuclear membrane. Such proteins in the outer nuclear membrane, including nesprins, Zyg12, and Klarsicht, contact actin and microtubule networks. Therefore, the nuclear skeleton and components of the cytoskeleton are connected, determining nuclear position and, when necessary, nuclear migration. Weakness in any component of this integrated cellular skeleton, including the lamina, may make the entire network fragile and the cell more susceptible to damage from recurrent mechanical strain.

Certain genes and signal transduction pathways are activated by mechanical strain. Impaired response to mechanical stimulation can attenuate transcriptional activation of mechanosensitive genes, some of which may be necessary in the heart for the development of compensatory hypertrophy (Nikolova et al., 2004). The role of the lamina in mechano-transduction has been directly investigated by subjecting lamin A and $C$ deficient mouse fibroblasts to mechanical strains (Lammerding et al., 2004). Under strain, these fibroblasts have increased nuclear deformation, defective mechanotransduction, attenuated strain-induced signaling and impaired viability. Thus, the separation between mechanical and gene expression models to explain the cell-specific and tissue-specific alterations in diseases caused by lamin mutations may be artificial and, in fact, abnormalities in response to mechanical stress may lead to aberrant responses in gene activation.

In the "gene expression" hypothesis, lamins A and C are considered essential for the proper tissue-specific expression of certain genes. Dynamic studies have shown that the motion of peripheral chromatin is constrained (Abney et al., 1997; Marshall et al., 1997; Chubb et al., 2002), likely as a result of its association with a stable interphase nuclear lamina-pore complex network (Aaronson and Blobel, 1975; Dwyer and Blobel, 1976; Broers et al., 1999; Moir et al., 2000b; Daigle et al., 2001). Silent genes are located preferentially in this peripheral chromatin whereas expressed genes are usually concentrated in the center of the nucleus (Cremer and Cremer, 2001). Repositioning of a chromatin region from the nuclear periphery to the nuclear core could alter transcriptional activity of genes within the region. Alterations in lamina structure induced by mutations in lamins $A$ and $C$ could therefore perturb normal chromatin compartmentalization and induce tissue-specific changes in gene expression.

The peripheral lamina, particularly A-type lamins, has been shown to play a scaffolding role for several proteins with gene regulatory functions. Lamins form complexes with integral inner nuclear membrane proteins that may immobilize transcription factors and other gene regulatory proteins such as retinoblastoma protein, heterochromatin protein 1, SREBP1, germ cell-less, Oct1, YT521-B and MOK2 (Mancini et al., 1994; Ozaki et al., 1994; Ye and Worman, 1996; Ye et al., 1997; Imai et al., 1997; Nili et al., 2001; Lloyd et al., 2002; Dreuillet et al., 2002; Wilkinson et al., 2003; Holaska et al., 2003; Haraguchi et al., 2004; Johnson et al., 2004). In association with retinoblastoma protein, the A-type lamina network can sequester a large panel of proteins that play a key role in cell cycle progression, such as PCNA, p21, CDK4, and cyclin D3 (Markiewicz et al., 2002, 2005; Favreau et al., 2004). Immobilization of hypophosphorylated retinoblastoma protein on an insoluble nuclear structure is a prerequisite for cell cycle arrest and cell differentiation. Cells lacking lamins $A$ and $C$ 
have a dramatic decrease in retinoblastoma protein due to proteosomal degradation, which is restored upon reexpression of lamin A (Johnson et al., 2004). Expression in myoblast cell lines of lamin A with a mutation that causes Emery-Dreifuss muscular dystrophy impairs myotube differentiation in correlation with the persistence of a high level of retinoblastoma protein phosphorylation and a low level of expression of the muscle-specific transcription factor myogenin (Favreau et al., 2004; Markiewicz et al., 2005). This strongly suggests a functional link between the lamina and proteins involved in cell cycle progression and cell differentiation.

\section{Concluding Remarks/Future Directions}

Our incomplete understanding of the basic functions of lamins and other nuclear envelope proteins makes understanding the pathogenesis of diseases caused by their mutations extremely difficult. Experimental designs have been hampered by the lack of simple "read outs" for the functions of lamins and other proteins. Except for assessing Smad activity in the case of MAN1 mutants and potentially sterol reductase activity in the case of LBR mutants, there are no easily measurable downstream consequences of, for example, abnormal A-type lamin function. Several studies have used nuclear morphology as a marker for A-type lamin function; however, nuclear morphological abnormalities in cells expressing mutant lamins are variable and difficult to quantify.

Future research will be facilitated by the identification of individual genes or functional groups of genes that are dependent on nuclear envelope protein function. Experiments using DNA microarrays have identified genes that are differentially expressed in cells lacking emerin and with mutant A-type lamins; however, the data so far are limited to fairly small studies (Tsukahara et al., 2002; Amati et al., 2004; Csoka et al., 2004b). Nonetheless, gene expression data obtained from DNA microarray studies of fibroblasts from only a small number of subjects with Hutchinson-Gilford progeria syndrome have been useful in examining the "correction" of the abnormal cellular phenotype when reducing the amount of the truncated prelamin A mutant in cells (Scaffidi and Misteli, 2005). Future statistically robust gene expression data obtained using large numbers of human samples and tissues from mouse models should be able to identify important pathways and functional groups of genes that are abnormally activated or repressed when nuclear envelope proteins are mutated or absent. Such results will be tremendously useful for evaluating the effects of mutant nuclear envelope proteins in cellular models of disease.

Animal models deficient in or expressing mutant nuclear envelope proteins have been useful models of human disease. Undoubtedly, additional animal models will be created in the future. Genetically altered mice deficient in nuclear envelope proteins or expressing mutants using either homologous recombination or transgenic approaches will likely be most applicable to understanding human disease physiology. However, as demonstrated by the models already available, all of the features of human disease may not be reproduced in mice. For example, while most of the human diseases caused by A-type lamin mutations are autosomal dominant, heterozygous $L$ mna null mice are apparently normal (Sullivan et al., 1999). 
Most importantly, collaborations between a broad range of physicians and scientists with different areas of expertise will be essential for understanding the multiple disorders caused by mutations in lamins and other nuclear envelope. The clinical phenotypes of affected human subjects span the disciplines of neurology, cardiology, endocrinology, metabolism, pediatrics, geriatrics, orthopedics, dermatology, hepatology and hematology. Collection of adequate human cell and tissue samples for experimental studies will require a major coordinated effort between physicians who traditionally have worked in very different areas and basic scientists. The experimental studies themselves will require the efforts of scientists with many different skills, including cell biologists, physiologists, geneticists, biochemists and bioinformaticists. Laudatory efforts to bring together diverse groups of researchers from around the world have been extremely rewarding (Bonne et al., 2002, 2003; Evans et al., 2004; Chadwick and Goode, 2005) and should be encouraged and financially supported in the future.

\section{Acknowledgements}

We thank Myriam Barre, Isabelle Duband-Goulet and Antoine Muchir for invaluable assistance with creating and designing the figures. H. J. W. is supported by the National Institutes of Health, Muscular Dystrophy Association and American Diabetes Association. J. C. C. is supported by Institut National de la Santé et de la Recherche Médicale, Centre National de la Recherche Scientifique and Association Française contre les Myopathies.

VII. Reference List

Aaronson, R. P., and Blobel G. (1975). Isolation of nuclear pore complexes in association with a lamina. Proc. Natl. Acad. Sci. U. S. A. 72, 1007-1011.

Abney, J. R., Cutler, B., Fillbach, M. L., Axelrod, D., and Scalettar, B. A. (1997). Chromatin dynamics in interphase nuclei and its implications for nuclear structure.

J. Cell Biol. 137, 1459-1468.

Aebi, U., Cohn, J., Buhle, L., and Gerace, L. (1986). The nuclear lamina is a meshwork of intermediate-type filaments. Nature 323, 560-564.

Agarwal, A. K., Fryns, J. P., Auchus, R. J., and Garg, A. (2003). Zinc metalloproteinase, ZMPSTE24, is mutated in mandibuloacral dysplasia. Hum. Molec. Genet. 12, 1995-2001.

Alsheimer, M., and Benavente, R. (1996). Change of karyoskeleton during mammalian spermatogenesis: expression pattern of nuclear lamin $\mathrm{C} 2$ and its regulation.

Exp. Cell Res. 228, 181-188.

Amati, F., Biancolella, M., D'Apice, M. R., Gambardella, S., Mango, R., Sbraccia, P., D'Adamo, M., Margiotti, K., Nardone, A., Lewis, M., and Novelli, G. (2004). Gene expression profiling of fibroblasts from a human progeroid disease (mandibuloacral dysplasia, MAD \#248370) through cDNA microarrays. Gene Expr. 12, 39-47.

Arimura, T., Helbling-Leclerc, A., Massart, C., Varnous, S., Niel, F., Lacene, E., Fromes, Y., Toussaint, M., Mura, A. M., Keller, D. I., Amthor, H., Isnard, R., Malissen, M., Schwartz, K., and Bonne, G. (2005). Mouse model carrying H222P-Lmna mutation develops muscular dystrophy and dilated cardiomyopathy similar to human striated muscle laminopathies. Hum. Mol. Genet. 14, 155-169. 
Aznar, J., and Vaya, A. (1981). Homozygous form of the Pelger-Huët leukocyte anomaly in man. Acta Haematol. $66,59-62$.

Barbie, D. A., Kudlow, B. A., Frock, R., Zhao, J., Johnson, B. R., Dyson, N., Harlow, E., and Kennedy, B. K. (2004). Nuclear reorganization of mammalian DNA synthesis prior to cell cycle exit. Mol. Cell Biol. 24, 595-607.

Basham, S. E., and Rose, L. S. (1999). Mutations in ooc-5 and ooc-3 disrupt oocyte formation and the reestablishment of asymmetric PAR protein localization in two-cell Caenorhabditis elegans embryos. Dev. Biol. 215, 253-263.

Basham, S. E., and Rose, L. S. (2001). The Caenorhabditis elegans polarity gene ooc-5 encodes a torsin-related protein of the AAA ATPase superfamily. Development 128, 4645-4656.

Beaudouin, J., Gerlich, D., Daigle, N., Eils, R., and Ellenberg, J. (2002). Nuclear envelope breakdown proceeds by microtubule-induced tearing of the lamina. Cell 108, 83-96.

Bechert, K., Lagos-Quintana, M., Harborth, J., Weber, K., and Osborn, M. (2003). Effects of expressing lamin A mutant protein causing Emery-Dreifuss muscular dystrophy and familial partial lipodystrophy in HeLa cells. Exp. Cell Res. 286, 75-86.

Beck, L. A., Hosick, T. J., and Sinensky, M. (1988). Incorporation of a product of mevalonic acid metabolism into proteins of Chinese hamster ovary cell nuclei.

J. Cell Biol. 107, 1307-1316.

Beck, L. A., Hosick, T. J., and Sinensky, M. (1990). Isoprenylation is required for the processing of the lamin A precursor. J. Cell Biol. 110, 1489-99.

Bednenko, J., Cingolani, G., and Gerace, L. (2003). Nucleocytoplasmic transport: navigating the channel. Traffic 4, 127-135.

Bergo, M. O., Gavino, B., Ross, J., Schmidt, W. K., Hong, C., Kendall, L. V., Mohr, A., Meta, M., Genant, H., Jiang, Y., Wisner, E. R., Van Bruggen, N., Carano, R. A., Michaelis, S., Griffey, S. M., and Young, S. G. (2002). Zmpste24 deficiency in mice causes spontaneous bone fractures, muscle weakness, and a prelamin A processing defect. Proc. Natl. Acad. Sci. U. S. A. 99, 13049-13054.

Berlin, R., Hedensio, B., Lilja, B., and Linder, L. (1967). Osteopoikilosis - a clinical and genetic study. Acta Med. Scand. 181, 305-314.

Best, S., Salvati, F., Kallo, J., Garner, C., Height, S., Thein, S. L., and Rees, D. C. (2003). Lamin B-receptor mutations in Pelger-Huët anomaly. Br. J. Haematol. 123, 542-544.

Biamonti, G., Giacca, M., Perini, G., Contreas, G., Zentilin, L., Weighardt, F., Guerra, M., Della Valle, G., Saccone, S., Riva, S, and Falaschi, A. (1992). The gene for a novel human lamin maps at a highly transcribed locus of chromosome 19 which replicates at the onset of S-phase. Mol. Cell. Biol. 12, 3499-3506.

Bione, S., Maestrini, E., Rivella, S., Mancini, M., Regis, S., Romeo, G., and Toniolo, D. (1994). Identification of a novel X-linked gene responsible for Emery-Dreifuss muscular dystrophy. Nat. Genet. 8, 323-327.

Bonne, G., Di Barletta, M. R., Varnous, S., Becane, H. M., Hammouda, E. H., Merlini, L., Muntoni, F., Greenberg, C. R., Gary, F., Urtizberea, J. A., Duboc, D., Fardeau, M., Toniolo, D., and Schwartz, K. (1999). Mutations in the gene encoding lamin A/C cause autosomal dominant Emery-Dreifuss muscular dystrophy. Nat. Genet. 21, $285-288$.

Bonne, G., Mercuri, E., Muchir, A., Urtizberea, A., Becane, H. M., Recan, D., Merlini, L., Wehnert, M., Boor, R., Reuner, U., Vorgerd, M., Wicklein, E. M., Eymard, B., Duboc, D., Penisson-Besnier, I., Cuisset, J. M., Ferrer, X., Desguerre, I., Lacombe, D., Bushby, K., Pollitt, C., Toniolo, D., Fardeau, M., Schwartz, K., and Muntoni, F. (2000). Clinical and molecular genetic spectrum of autosomal dominant Emery-Dreifuss muscular dystrophy due to mutations of the lamin A/C gene. Ann. Neurol. 48, 170-180. 
Bonne, G., Capeau, J., De Visser, M., Duboc, D., Merlini, L., Morris, G. E., Muntoni, F., Recan, D., Sewry, C., Squarzoni, S., Stewart, C., Talim, B., van der Kooi, A., Worman, H., and Schwartz, K. (2002). 82nd ENMC international workshop, 5th international Emery-Dreifuss muscular dystrophy (EDMD) workshop, 1st Workshop of the MYO-CLUSTER project EUROMEN (European muscle envelope nucleopathies), 15-16 September 2000, Naarden, The Netherlands. Neuromuscul. Disord. 12, 187-194.

Bonne, G., Yaou, R. B., Beroud, C., Boriani, G., Brown, S., de Visser, M., Duboc, D., Ellis, J., HausmanowaPetrusewicz, I., Lattanzi, G., Merlini, L., Morris, G., Muntoni, F., Opolski, G., Pinto, Y. M., Sangiuolo, F., Toniolo, D., Trembath, R., van Berlo, J. H., van der Kooi, A. J., and Wehnert, M. (2003). 108th ENMC International Workshop, 3rd Workshop of the MYO-CLUSTER project: EUROMEN, 7th International Emery-Dreifuss Muscular Dystrophy (EDMD) Workshop, 13-15 September 2002, Naarden, The Netherlands. Neuromuscul. Disord. 13, 508-515.

Boyle, S., Gilchrist, S., Bridger, J. M., Mahy, N. L., Ellis, J. A., and Bickmore, W. A. (2001). The spatial organization of human chromosomes within the nuclei of normal and emerin-mutant cells. Hum. Mol Genet. 10, $211-219$.

Brodsky, G. L., Muntoni, F., Miocic, S., Sinagra, G., Sewry, C., and Mestroni, L. (2000). Lamin A/C gene mutation associated with dilated cardiomyopathy with variable skeletal muscle involvement. Circulation 101, $473-476$.

Broers, J. L., Machiels, B. M., van Eys, G. J., Kuijpers, H. J., Manders, E. M., van Driel, R., and Ramaekers, F. C. (1999). Dynamics of the nuclear lamina as monitored by GFP-tagged A-type lamins. J. Cell Sci. 112, 3463-3475.

Broers, J. L., Peeters, E. A., Kuijpers, H. J., Endert, J., Bouten, C. V., Oomens, C. W., Baaijens, F. P., and Ramaekers, F. C. (2004). Decreased mechanical stiffness in $L M N A-/$-cells is caused by defective nucleocytoskeletal integrity: implications for the development of laminopathies. Hum. Mol. Genet. 13, 2567-2580.

Broers, J. L., Kuijpers, H. J., Östlund, C., Worman, H. J., Endert, J., and Ramaekers, F. C. (2005). Both lamin A and lamin $\mathrm{C}$ mutations cause lamina instability as well as loss of internal nuclear lamin organization. Exp. Cell Res. 304, 582-592.

Brown, S. C., Muntoni, F., and Sewry, C. A. (2001). Non-sarcolemmal muscular dystrophies. Brain Pathol. 11, 193205.

Brown, W. T. (1979). Human mutations affecting aging - a review. Mech. Aging Dev. 9, 325-336.

Buendia, B., and Courvalin, J. C. (1997). Domain-specific disassembly and reassembly of nuclear membranes during mitosis. Exp. Cell Res. 230, 133-144.

Burke, B., and Stewart, C. L. (2002). Life at the edge: the nuclear envelope and human disease. Nat. Rev. Mol. Cell Biol. 3, 575-585.

Burton, E. A., and Davies, K. E. (2002). Muscular dystrophy - reason for optimism?

Cell 108, 5-8.

Buschke, A., and Ollendorff, H. (1928). Ein fall von dermatofibrosis lenticularis disseminata. Derm. Wochenschr. 86, 257-262.

Cai, M., Huang, Y., Ghirlando, R., Wilson, K. L., Craigie, R., and Clore, G. M. (2001). Solution structure of the constant region of nuclear envelope protein LAP2 reveals two LEM-domain structures: one binds BAF and the other binds DNA. EMBO J. 20, 4399-4407.

Campbell, C. J., Papademetriou, T., and Bonfiglio, M. (1968). Melorheostosis. A report of the clinical, roentgenographic, and pathological findings in fourteen cases. J. Bone Joint Surg. Am. 50, 1281-1304.

Cance, W. G., Chaudhary, N., Worman, H. J., Blobel, G. and Cordon-Cardo, C. (1992). Expression of the nuclear lamins in normal and neoplastic human tissues. J. Exp. Clin. Cancer Res. 11, 233-246.

Cao, H., and Hegele, R. A. (2000). Nuclear lamin A/C R482Q mutation in Canadian kindreds with Dunnigan-type familial partial lipodystrophy. Hum. Mol. Genet. 9, 109-112. 
Cao, H., and Hegele, R. A. (2003). LMNA is mutated in Hutchinson-Gilford progeria (MIM 176670) but not in Wiedemann-Rautenstrauch progeroid syndrome (MIM 264090). J. Hum. Genet. 48, 271-274.

Capanni, C., Cenni, V., Mattioli, E., Sabatelli, P., Ognibene, A., Columbaro, M., Parnaik, V. K., Wehnert, M., Maraldi, N. M., Squarzoni, S., Lattanzi, G. (2003). Failure of lamin A/C to functionally assemble in R482L mutated familial partial lipodystrophy fibroblasts: altered intermolecular interaction with emerin and implications for gene transcription. Exp. Cell Res. 291, 122-134.

Caux, F., Dubosclard, E., Lascols, O., Buendia, B., Chazouilleres, O., Cohen, A., Courvalin, J. C., Laroche, L., Capeau, J., Vigouroux, C., and Christin-Maitre, S. (2003). A new clinical condition linked to a novel mutation in lamins $\mathrm{A}$ and $\mathrm{C}$ with generalized lipoatrophy, insulin-resistant diabetes, disseminated leukomelanodermic papules, liver steatosis, and cardiomyopathy. J. Clin. Endocrinol. Metab. 88, 1006-1013.

Chadwick, D. J. and Goode, J. (2005). "Novartis Foundation Symposium 264 Nuclear Organization in Development and Disease," John Wiley and Sons, Chichester.

Chaudhary, N., and Courvalin, J. C. (1993). Stepwise reassembly of the nuclear envelope at the end of mitosis. J. Cell Biol. 122, 295-306.

Chen, L., Lee, L., Kudlow, B. A., Dos Santos, H. G., Sletvold, O., Shafeghati, Y.,.Botha, E. G., Garg, E., Hanson, N. B., Martin, G. M., Mian, I. S., Kennedy, B. K., and Oshima, J. (2003). LMNA mutations in atypical Werner's syndrome. Lancet 362, 440-445.

Chigira, M., Kato, K., Mashio, K., and Shinozaki, T. (1991) Symmetry of bone lesions in osteopoikilosis: report of 4 cases. Acta Ortho. Scand. 62, 495-496.

Chubb, J. R., Boyle, S., Perry, P., and Bickmore, W. A. (2002). Chromatin motion is constrained by association with nuclear compartments in human cells. Curr. Biol. 12, 439-445.

Clements, L., Manilal, S., Love, D. R., and Morris, G. E. (2000). Direct interaction between emerin and lamin A. Biochem. Biophys. Res. Commun. 267, 709-714.

Cohen, M., Lee, K. K., Wilson, K. L., and Gruenbaum, Y. (2001). Transcriptional repression, apoptosis, human disease and the functional evolution of the nuclear lamina. Trends Biochem Sci. 26, 41-47.

Cohn, R. D., and Campbell, K. P. (2000). Molecular basis of muscular dystrophies.

Muscle Nerve 23, 1456-1471.

Corrigan, D. P., Kuszczak, D., Rusinol, A. E., Thewke, D. P., Hrycyna, C. A., Michaelis, S., and Sinensky, M. S. (2005). Prelamin A endoproteolytic processing in vitro by recombinant Zmpste24. Biochem. J. In press.

Courvalin, J. C., Segil, N., Blobel, G., and Worman, H. J. (1992). The lamin B receptor of the inner nuclear membrane undergoes mitosis-specific phosphorylation and is a substrate for p34cdc2-type protein kinase. J. Biol. Chem. 267, 19035-19038.

Cremer, T., and Cremer, C. (2001). Chromosome territories, nuclear architecture and gene regulation in mammalian cells. Nat. Rev. Genet. 2, 292-301.

Cronshaw JM, Krutchinsky AN, Zhang W, Chait BT, and Matunis MJ. (2002). Proteomic analysis of the mammalian nuclear pore complex. J. Cell Biol. 158, 915-927.

Cronshaw, J. M., and Matunis, M. J. (2004). The nuclear pore complex: disease associations and functional correlations. Trends Endocrinol. Metab. 15, 34-39.

Csoka, A. B., Cao, H., Sammak, P. J., Constantinescu, D., Schatten, G. P., and Hegele, R. A. (2004a). Novel lamin A/C gene (LMNA) mutations in atypical progeroid syndromes. J. Med. Genet. 41, 304-308.

Csoka, A. B., English, S. B., Simkevich, C. P., Ginzinger, D. G., Butte, A. J., Schatten, G. P., Rothman, F. G., and Sedivy, J. M. (2004b). Genome-scale expression profiling of Hutchinson-Gilford progeria syndrome reveals 
widespread transcriptional misregulation leading to mesodermal/mesenchymal defects and accelerated atherosclerosis. Aging Cell 3, 235-243.

Cutler, D. A., Sullivan, T., Marcus-Samuels, B., Stewart, C. L., and Reitman, M. L. (2002). Characterization of adiposity and metabolism in Lmna-deficient mice. Biochem. Biophys. Res. Commun. 291, 522-527.

Cutler, D. L., Kaufmann, S., and Freidenberg, G. R. (1991). Insulin-resistant diabetes mellitus and hypermetabolism in mandibuloacral dysplasia: a newly recognized form of partial lipodystrophy. J. Clin. Endocrinol. Metab. 73, 10561061.

Daigle, N., Beaudouin, J., Hartnell, L., Imreh, G., Hallberg, E., Lippincott-Schwartz, J., and Ellenberg, J. (2001). Nuclear pore complexes form immobile networks and have a very low turnover in live mammalian cells. J. Cell Biol. 154, 71-84.

Dalkilic, I., and Kunkel, L. M. (2003). Muscular dystrophies: genes to pathogenesis.

Curr. Opin. Genet. Dev. 13, 231-238.

D'Apice, M. R., Tenconi, R., Mammi, I., van den Ende, J., and Novelli, G. (2004). Paternal origin of LMNA mutations in Hutchinson-Gilford progeria. Clin. Genet. 65, 52-54.

DeBusk, F. L. (1972). The Hutchinson-Gilford progeria syndrome. J. Pediat. 80, 697-724.

De Sandre-Giovannoli, A., Bernard, R., Cau, P., Navarro, C., Amiel, J., Boccaccio, I., Lyonnet, S., Stewart, C. L., Munnich, A., Le Merrer, M., and Levy, N. (2003). Lamin A truncation in Hutchinson-Gilford progeria. Science 300, 2055.

Dhe-Paganon, S., Werner, E. D., Chi, Y. I., and Shoelson, S. E. (2002). Structure of the globular tail of nuclear lamin. J. Biol. Chem. 277, 17381-17384.

Dimitrova, D. S., and Berezney, R. (2002). The spatio-temporal organization of DNA replication sites is identical in primary, immortalized and transformed mammalian cells. J. Cell Sci. 115, 4037-4051.

Doring, V., and Stick, R. (1990). Gene structure of nuclear lamin LIII of Xenopus laevis; a model for the evolution of IF proteins from a lamin-like ancestor. EMBO J. 9, 4073-4081.

Dreuillet, C., Tillit, J., Kress, M., and Ernoult-Lange, M. (2002). In vivo and in vitro interaction between human transcription factor MOK2 and nuclear lamin A/C. Nucleic Acids Res. 30, 4634-4642.

Duband-Goulet, I., and Courvalin, J. C. (2000). Inner nuclear membrane protein LBR preferentially interacts with DNA secondary structures and nucleosomal linker.

Biochemistry 39, 6483-6488.

Dunnigan, M. G., Cochrane, M.A., Kelly, A., and Scott, J. W. (1974). Familial lipoatrophic diabetes with dominant transmission. A new syndrome. Q. J. Med. 43, 33-48.

Dwyer, N., and Blobel, G. (1976). A modified procedure for the isolation of a pore complex-lamina fraction from rat liver nuclei. J. Cell Biol. 70, 581-591.

Ellenberg, J., Siggia, E. D., Moreira, J. E., Smith, C. L., Presley, J. F., Worman, H. J., and Lippincott-Schwartz, J. (1997). Nuclear membrane dynamics and reassembly in living cells: targeting of an inner nuclear membrane protein in interphase and mitosis.

J. Cell Biol. 138, 1193-1206.

Ellis, J. A., Craxton, M., Yates, J. R., and Kendrick-Jones, J. (1998). Aberrant intracellular targeting and cell cycledependent phosphorylation of emerin contribute to the Emery-Dreifuss muscular dystrophy phenotype. J. Cell Sci. 111, 781-792.

Ellis, J. A., Yates, J. R., Kendrick-Jones, J., and Brown, C. A. (1999). Changes at P183 of emerin weaken its protein-protein interactions resulting in X-linked Emery-Dreifuss muscular dystrophy. Hum. Genet. 104, $262-268$. 
Ellis, J. A., Brown, C. A., Tilley, L. D., Kendrick-Jones, J., Spence, J. E., and Yates, J. R. (2000). Two distal mutations in the gene encoding emerin have profoundly different effects on emerin protein expression. Neuromuscul. Disord. 10, 24-30.

Emery, A. E., and Dreifuss, F. E. (1996). Unusual type of benign x-linked muscular dystrophy. J. Neurol. Neurosurg. Psychiatry 29, 338-342.

Emery, A.E. (1989). Emery-Dreifuss syndrome. J. Med. Genet. 26, 637-641.

Eriksson, M., Brown, W. T., Gordon, L. B., Glynn, M. W., Singer, J., Scott, L., Erdos, M. R., Robbins, C. M., Moses, T. Y., Berglund, P., Dutra, A., Pak, E., Durkin, S., Csoka, A. B., Boehnke, M., Glover, T. W., and Collins, F. S. (2003). Recurrent de novo point mutations in lamin A cause Hutchinson-Gilford progeria syndrome. Nature 423, $293-298$.

Evans, D. E., Bryant, J. A., and Hutchison, C. (2004). "SEB Symposium Series Volume 56: The Nuclear Envelope," Garland/Bios Scientific Publishers, Abingdon.

Fahn, S. (1991). The genetics of idiopathic torsion dystonia. Int. J. Neurol. 25, 70-80.

Fahrenkrog, B., and Aebi, U. (2003). The nuclear pore complex: nucleocytoplasmic transport and beyond. Nat. Rev. Mol. Cell Biol. 4, 757-66.

Fairley, E. A., Kendrick-Jones, J., and Ellis, J. A. (1999). The Emery-Dreifuss muscular dystrophy phenotype arises from aberrant targeting and binding of emerin at the inner nuclear membrane. J. Cell Sci. 112, 2571-2582.

Farnsworth, C. C., Wolda, S. L., Gelb, M. H., and Glomset, J. A. (1989). Human lamin B contains a farnesylated cysteine residue. J. Biol. Chem. 264, 20422-20429.

Fatkin, D., MacRae, C., Sasaki, T., Wolff, M. R., Porcu, M., Frenneaux, M., Atherton, J., Vidaillet, H. J., Jr., Spudich, S., De Girolami, U., Seidman, J. G., Seidman, C., Muntoni, F., Muehle, G., Johnson, W., and McDonough, B. (1999). Missense mutations in the rod domain of the lamin A/C gene as causes of dilated cardiomyopathy and conductionsystem disease. N. Engl. J. Med. 341, 1715-1724.

Favreau, C., Dubosclard, E., Östlund, C., Vigouroux, C., Capeau, J., Wehnert, M., Higuet, D., Worman, H. J., Courvalin, J. C., and Buendia, B. (2003). Expression of lamin A mutated in the carboxyl-terminal tail generates an aberrant nuclear phenotype similar to that observed in cells from patients with Dunnigan-type partial lipodystrophy and Emery-Dreifuss muscular dystrophy. Exp. Cell Res. 282, 14-23.

Favreau, C., Higuet, D., Courvalin, J. C., and Buendia, B. (2004). Expression of a mutant lamin A that causes Emery-Dreifuss muscular dystrophy inhibits in vitro differentiation of C2C12 myoblasts. Mol. Cell Biol. 24, 14811492.

Fawcett, D. W. (1966). On the occurrence of a fibrous lamina on the inner aspect of the nuclear envelope in certain cells of vertebrates. Am. J. Anat. 119, 129-145.

Fenichel, G. M., Sul, Y. C., Kilroy, A. W., and Blouin, R. (1982). An autosomal-dominant dystrophy with humeropelvic distribution and cardiomyopathy. Neurology 32, 1399-1401.

Fidzianska, A, and Hausmanowa-Petrusewicz, I. (2003). Architectural abnormalities in muscle nuclei. Ultrastructural differences between $X$-linked and autosomal dominant forms of EDMD. J. Neurol. Sci. 210, 47-51.

Fisher, D. Z., Chaudhary, N., and Blobel G. (1986). cDNA sequencing of nuclear lamins A and C reveals primary and secondary structural homology to intermediate filament proteins. Proc. Natl. Acad. Sci. U. S. A. 83, 6450-6454.

Fisher, P. A., Berrios, M., and Blobel, G. (1982). Isolation and characterization of a proteinaceous subnuclear fraction composed of nuclear matrix, peripheral lamina, and nuclear pore complexes from embryos of Drosophila melanogaster. J. Cell Biol. 92, 674-686. 
Foisner, R., and Gerace, L. (1993). Integral membrane proteins of the nuclear envelope interact with lamins and chromosomes, and binding is modulated by mitotic phosphorylation. Cell 73, 1267-1279.

Fong, L. G., Ng, J. K., Meta, M., Cote, N., Yang, S. H., Stewart, C. L., Sullivan, T., Burghardt, A., Majumdar, S., Reue, K., Bergo, M. O., and Young, S. G. (2004). Heterozygosity for Lmna deficiency eliminates the progeria-like phenotypes in Zmpste24-deficient mice. Proc. Natl. Acad. Sci. U. S. A. 101, 18111-18116.

Forissier, J. F., Bonne, G., Bouchier, C., Duboscq-Bidot, L., Richard, P., Wisnewski, C., Briault, S., Moraine, C., Dubourg, O., Schwartz, K., and Komajda, M. (2003). Apical left ventricular aneurysm without atrio-ventricular block due to a lamin $A / C$ gene mutation.

Eur. J. Heart Fail. 5, 821-825.

Freidenberg, G. R., Cutler, D. L., Jones, M. C., Hall, B., Mier, R. J., Culler, F., Jones, K. L., Lozzio, C., and Kaufmann, S. (1992). Severe insulin resistance and diabetes mellitus in mandibuloacral dysplasia. Am. J. Dis. Child. 146, 9399.

Fridkin, A., Mills, E., Margalit, A., Neufeld, E., Lee, K. K., Feinstein, N., Cohen, M., Wilson, K. L., and Gruenbaum, Y. (2004). Matefin, a Caenorhabditis elegans germ line-specific SUN-domain nuclear membrane protein, is essential for early embryonic and germ cell development. Proc. Natl. Acad. Sci. U. S. A. 101, 6987-6992.

Furukawa, K. and Hotta, Y. (1993). cDNA cloning of a germ cell specific lamin B3 from mouse spermatocytes and analysis of its function by ectopic expression in somatic cells. EMBO J. 12, 97-106.

Furukawa, K., Inagaki, H., and Hotta, Y. (1994). Identification and cloning of an mRNA coding for a germ cellspecific A-type lamin in mice. Exp. Cell Res. 212, 426-430.

Garg, A., Vinaitheerthan, M., Weatherall, P. T., and Bowcock, A. M. (2001). Phenotypic heterogeneity in patients with familial partial lipodystrophy (Dunnigan variety) related to the site of missense mutations in lamin A/C gene. J. Clin. Endocrinol. Metab. 86, 59-65.

Garg, A., Speckman, R. A., and Bowcock, A. M. (2002). Multisystem dystrophy syndrome due to novel missense mutations in the amino-terminal head and alpha-helical rod domains of the lamin A/C gene. Am. J. Med. 112, 549555.

Gerace, L., Blum, A., and Blobel, G. (1978). Immunocytochemical localization of the major polypeptides of the nuclear pore complex-lamina fraction. Interphase and mitotic distribution. J. Cell Biol. 79, 546-566.

Gerace, L., and Blobel, G. (1980). The nuclear envelope lamina is reversibly depolymerized during mitosis. Cell 19, 277-287.

Gerace, L. (2004). TorsinA and torsion dystonia: unraveling the architecture of the nuclear envelope. Proc. Natl. Acad. Sci. U. S. A. 101, 8839-8840.

Gilchrist, S., Gilbert, N., Perry, P., Östlund, C., Worman, H. J., and Bickmore, W. A. (2004). Altered protein dynamics of disease-associated lamin A mutants. BMC Cell Biol. 5, 46.

Gilford, H. (1904). Ateleiosis and progeria: continuous youth and premature old age. Brit. Med. J. 2, 914-918.

Giro, M. G., Duvic, M., Smith, L. T., Kennedy, R., Rapini, R., Arnett, F. C., and Davidson, J. M. (1992). BuschkeOllendorff syndrome associated with elevated elastin production by affected skin fibroblasts in culture. J. Invest.

Derm. 99, 129-137.

Glass, C. A., Glass, J. R., Taniura, H., Hasel, K. W., Blevitt , J. M., and Gerace, L. (1993). The alpha-helical rod domain of human lamins $A$ and $C$ contains a chromatin binding site. EMBO J. 12, 4413-4424.

Goldberg, M., Harel, A., Brandeis, M., Rechsteiner, T., Richmond, T. J., Weiss, A. M., and Gruenbaum, Y. (1999). The tail domain of lamin Dm0 binds histones H2A and H2B. Proc. Natl. Acad. Sci. U. S. A. 96, 2852-2857. 
Goldman, A. E., Maul, G., Steinert, P. M., Yang, H. Y., and Goldman, R. D. (1986). Keratin-like proteins that coisolate with intermediate filaments of BHK-21 cells are nuclear lamins. Proc. Natl. Acad. Sci. U. S. A. 83, 3839-3843.

Goldman, R. D., Gruenbaum, Y., Moir, R. D., Shumaker, D. K., and Spann, T. P. (2002). Nuclear lamins: building blocks of nuclear architecture. Genes Dev. 16, 533-547.

Goldman, R. D., Shumaker, D. K., Erdos, M. R., Eriksson, M., Goldman, A. E., Gordon, L. B., Gruenbaum, Y., Khuon, S., Mendez, M., Varga, R., and Collins, F. S. (2004) Accumulation of mutant lamin A causes progressive changes in nuclear architecture in Hutchinson-Gilford progeria syndrome. Proc. Natl. Acad. Sci. U. S. A. 101, 8963-8968.

Gonzalez-Alegre, P., and Paulson, H. L. (2004). Aberrant cellular behavior of mutant torsinA implicates nuclear envelope dysfunction in DYT1 dystonia. J. Neurosci. 24, 2593-2601.

Goodchild, R. E., and Dauer, W. T. (2004). Mislocalization to the nuclear envelope: an effect of the dystoniacausing torsinA mutation. Proc. Natl. Acad. Sci. U. S. A. 101, 847-852.

Goodchild, R. E., and Dauer, W. T. (2005). The AAA+ protein torsonA interacts with a conserved domain present in LAP1 and a novel ER protein. J. Cell Biol. In press.

Greenberg, C. R., Rimoin, D. L., Gruber, H. E., DeSa, D. J., Reed, M., and Lachman, R. S. (1988). A new autosomal recessive lethal chondrodystrophy with congenital hydrops. Am. J. Med. Genet. 29, 623-632.

Gruber, J., Lampe, T., Osborn, M., and Weber, K. (2005). RNAi of FACE1 protease results in growth inhibition of human cells expressing lamin A: implications for Hutchinson-Gilford progeria syndrome. J. Cell Sci. 118, 689-696.

Gruenbaum, Y., Lee, K. K., Liu, J., Cohen, M., and Wilson, K. L. (2002). The expression, lamin-dependent localization and RNAi depletion phenotype for emerin in C. elegans. J. Cell Sci. 115, 923-929.

Guilly, M. N., Bensussan, A., Bourge, J. F., Bornens, M., and Courvalin, J. C. (1987). A human T lymphoblastic cell line lacks lamins A and C. EMBO J. 6, 3795-3799.

Guilly, M. N., Kolb, J. P., Gosti, F., Godeau, F., and Courvalin, J. C. (1990). Lamins A and C are not expressed at early stages of human lymphocyte differentiation. Exp. Cell Res. 189, 145-147.

Hallberg, E., Wozniak, R. W., and Blobel ,G. (2003). An integral membrane protein of the pore membrane domain of the nuclear envelope contains a nucleoporin-like region.

J. Cell Biol. 122, 513-521.

Haraguchi, T., Koujin, T., Hayakawa, T., Kaneda, T., Tsutsumi, C., Imamoto, N., Akazawa, C., Sukegawa, J., Yoneda, Y., and Hiraoka, Y. (2000). Live fluorescence imaging reveals early recruitment of emerin, LBR, RanBP2, and Nup153 to reforming functional nuclear envelopes. J. Cell Sci. 113, 779-794.

Haraguchi, T., Holaska, J. M., Yamane, M., Koujin, T., Hashiguchi, N., Mori, C., Wilson, K. L., and Hiraoka, Y. (2004). Emerin binding to Btf, a death-promoting transcriptional repressor, is disrupted by a missense mutation that causes Emery-Dreifuss muscular dystrophy. Eur. J. Biochem. 271, 1035-1045.

Harborth, J., Elbashir, S. M., Bechert, K., Tuschl, T., and Weber, K. (2001). Identification of essential genes in cultured mammalian cells using small interfering RNAs. J. Cell Sci. 114, 4557-4565.

Hawryluk-Gara, L. A., Shibuya, E. K., and Wozniak, R. W. (2005). Vertebrate Nup53 interacts with the nuclear lamina and Is required for the assembly of a Nup93-containing complex. Mol. Biol. Cell In press.

Heald, R., and McKeon, F. (1990). Mutations of phosphorylation sites in lamin A that prevent nuclear lamina disassembly in mitosis. Cell $61,579-589$.

Hellemans, J., Preobrazhenska, O., Willaert, A., Debeer, P., Verdonk, P. C., Costa, T., Janssens, K., Menten, B., Van Roy, N., Vermeulen, S. J., Savarirayan, R., Van Hul, W., Vanhoenacker, F., Huylebroeck, D., De Paepe, A., Naeyaert, J. M., Vandesompele, J., Speleman, F., Verschueren, K., Coucke, P. J., and Mortier, G. R. (2004). Loss-of-function 
mutations in LEMD3 result in osteopoikilosis, Buschke-Ollendorff syndrome and melorheostosis. Nat. Genet. 36, 1213-1218.

Herrmann, H., and Aebi, U. (2004). Intermediate filaments: molecular structure, assembly mechanism, and integration into functionally distinct intracellular scaffolds. Annu. Rev. Biochem. 73, 749-789.

Hodzic, D. M., Yeater, D. B., Bengtsson, L., Otto, H., and Stahl, P. D. (2004). Sun2 is a novel mammalian inner nuclear membrane protein. J. Biol. Chem. 279, 25805-25812.

Hoffmann, K., Dreger, C. K., Olins, A. L., Olins, D. E., Shultz, L. D., Lucke, B., Karl, H., Kaps, R., Muller, D., Vaya, A., Aznar, J., Ware, R. E., Sotelo Cruz, N., Lindner, T. H., Herrmann, H., Reis, A., and Sperling, K. (2002). Mutations in the gene encoding the lamin B receptor produce an altered nuclear morphology in granulocytes (Pelger-Huët anomaly). Nat. Genet. 31, 410-414.

Höger, T. H., Zatloukal, K., Waizenegger, I., and Krohne, G. (1990). Characterization of a second highly conserved B-type lamin present in cells previously thought to contain only a single B-type lamin. Chromosoma 99, 379-390.

Holaska, J. M., Lee, K. K., Kowalski, A. K., and Wilson, K. L. (2003). Transcriptional repressor germ cell-less (GCL) and barrier to autointegration factor (BAF) compete for binding to emerin in vitro. J. Biol. Chem. 278, 6969-6975.

Holaska, J. M., Kowalski, A. K., and Wilson, K. L. (2004). Emerin caps the pointed end of actin filaments: evidence for an actin cortical network at the nuclear inner membrane.

PLoS Biol. 2, E231.

Holmer, L., Pezhman, A., and Worman, H. J. (1998). The human lamin B receptor/sterol reductase multigene family. Genomics 54, 469-476.

Holt, I., Östlund, C., Stewart, C. L., Man, N., Worman, H. J., and Morris, G. E. (2003). Effect of pathogenic missense mutations in lamin A on its interaction with emerin in vivo. J. Cell Sci. 116, 3027-3035.

Hutchinson, J. (1886). Case of congenital absence of hair, with atrophic condition of the skin and its appendages, in a boy whose mother had been almost wholly bald from alopecia areata from the age of six. Lancet I, 923.

Hutchison, C. J., Alvarez-Reyes, M., and Vaughan, O. A. (2001). Lamins in disease: why do ubiquitously expressed nuclear envelope proteins give rise to tissue-specific disease phenotypes? J. Cell Sci. 114, 9-19.

Hutchison, C. J., and Worman, H. J. (2004). A-type lamins: guardians of the soma?

Nat. Cell Biol. 6, 1062-1067.

Huët, G. J. (1932). Ueber eine bisher unbekannte familiaere Anomalie der Leukocyten. Klin. Wochenschr. 11, 1264-1266.

Imai, S., Nishibayashi, S., Takao, K., Tomifuji, M., Fujino, T., Hasegawa, M., and Takano, T. (1997). Dissociation of Oct-1 from the nuclear peripheral structure induces the cellular aging-associated collagenase gene expression. Mol. Biol. Cell. 8, 2407-2419.

Jackson, S. N., Howlett, T. A., McNally, P. G., O'Rahilly, S., and Trembath, R. C. (1997). Dunnigan-Köbberling syndrome: an autosomal dominant form of partial lipodystrophy. Q. J. Med. 90, 27-36.

Jackson, S. N., Pinkney, J., Bargiotta, A., Veal, C. D., Howlett, T. A., McNally, P. G., Corral, R., Johnson, A., and Trembath, R. C. (1998). A defect in the regional deposition of adipose tissue (partial lipodystrophy) is encoded by a gene at chromosome 1q. Am. J. Hum. Genet. 63, 534-540.

Jagatheesan, G., Thanumalayan, S., Muralikrishna, B., Rangaraj, N., Karande, A. A., and Parnaik, V. K. (1999). Colocalization of intranuclear lamin foci with RNA splicing factors. J. Cell Sci. 112, 4651-4661.

Johnson, B. R., Nitta, R. T., Frock, R. L., Mounkes, L., Barbie, D. A., Stewart, C. L., Harlow, E., and Kennedy, B. K. (2004). A-type lamins regulate retinoblastoma protein function by promoting subnuclear localization and preventing proteasomal degradation. 
Proc. Natl. Acad. Sci. U. S. A. 101, 9677-9682.

Kennedy, B. K., Barbie, D. A., Classon, M., Dyson, N., and Harlow, E. (2000). Nuclear organization of DNA replication in primary mammalian cells. Genes Dev. 14, 2855-2868.

Kilic, F., Dalton, M. B., Burrell, S. K., Mayer, J. P., Patterson, S. D., and Sinensky, M. (1997). In vitro assay and characterization of the farnesylation-dependent prelamin A endoprotease. J. Biol. Chem. 272, 5298-5304.

Klein, A., Hussar, A. E., and Bornstein, S. (1955). Pelger-Huët anomaly of the leukocytes. N. Engl. J. Med. 253, 1057-1062.

Köbberling, J., Willms, B., Kattermann, R., and Creutzfeldt, W. (1975). Lipodystrophy of the extremities. A dominantly inherited syndrome associated with lipatrophic diabetes. Humangenetik 29, 111-120.

Koh, Y. H., Rehfeld, K., and Ganetzky, B. (2004). A Drosophila model of early onset torsion dystonia suggests impairment in TGF-beta signaling. Hum. Mol. Genet. 13, 2019-2030.

Krimm, I., Östlund, C., Gilquin, B., Couprie, J., Hossenlopp, P., Mornon, J. P., Bonne, G., Courvalin, J. C., Worman, H. J., and Zinn-Justin, S. (2002). The Ig-like structure of the C-terminal domain of lamin A/C, mutated in muscular dystrophies, cardiomyopathy, and partial lipodystrophy. Structure 10, 811-823.

Krohne, G., Debus, E., Osborn, M., Weber, K., and Franke, W. W. (1984). A monoclonal antibody against nuclear lamina proteins reveals cell type-specificity in Xenopus laevis. Exp. Cell Res. 150, 47-59.

Krohne, G., Wolin, S. L., McKeon, F. D., Franke, W. W., and Kirschner, M. W. (1987). Nuclear lamin LI of Xenopus laevis: cDNA cloning, amino acid sequence and binding specificity of a member of the lamin B subfamily. EMBO J. 6, 3801-3808.

Kumaran, R. I., Muralikrishna, B., and Parnaik, V. K. (2002). Lamin A/C speckles mediate spatial organization of splicing factor compartments and RNA polymerase II transcription. J. Cell Biol. 159, 783-793.

Laguri, C., Gilquin, B., Wolff, N., Romi-Lebrun, R., Courchay, K., Callebaut, I., Worman, H. J., and Zinn-Justin, S. (2001). Structural characterization of the LEM motif common to three human inner nuclear membrane proteins. Structure 9, 503-511.

Lammerding, J., Schulze, P. C., Takahashi, T., Kozlov, S., Sullivan, T., Kamm, R. D., Stewart, C. L., and Lee, R. T. (2004). Lamin A/C deficiency causes defective nuclear mechanics and mechanotransduction. J. Clin. Invest. 113, 370-378.

Lang, C., Paulin-Levasseur, M., Gajewski, A., Alsheimer, M., Benavente, R., and Krohne. G. (1999). Molecular characterization and developmentally regulated expression of Xenopus lamina-associated polypeptide 2 (XLAP2). J. Cell Sci. 112, 749-759.

Lebel, S., Lampron, C., Royal, A., and Raymond, Y. (1987). Lamins A and C appear during retinoic acid-induced differentiation of mouse embryonal carcinoma cells.

J. Cell Biol. 105, 1099-1104.

Lee, K. K., Haraguchi, T., Lee, R. S., Koujin, T., Hiraoka, Y., and Wilson, K. L. (2001) Distinct functional domains in emerin bind lamin A and DNA-bridging protein BAF. J. Cell Sci. 114, 4567-4573.

Lee, K. K., Starr, D., Cohen, M., Liu, J., Han, M., Wilson, K. L., and Gruenbaum Y. (2002). Lamin-dependent localization of UNC-84, a protein required for nuclear migration in Caenorhabditis elegans. Mol. Biol. Cell 13, 892901.

Leung, G. K., Schmidt, W. K., Bergo, M. O., Gavino, B., Wong, D. H., Tam, A., Ashby, M. N., Michaelis, S., and Young, S. G. (2001). Biochemical studies of Zmpste24-deficient mice. J. Biol. Chem. 276, 29051-29058.

Lin, F., and Worman, H. J. (1993). Structural organization of the human gene encoding nuclear lamin A and nuclear lamin C. J. Biol. Chem. 268, 16321-16326. 
Lin, F., and Worman, H. J. (1995). Structural organization of the human gene (LMNB1) encoding nuclear lamin B1. Genomics 27, 230-236.

Lin, F., Blake, D. L., Callebaut, I., Skerjanc, I. S., Holmer, L., McBurney, M. W., Paulin-Levasseur, M., and Worman, H. J. (2000). MAN1, an inner nuclear membrane protein that shares the LEM domain with lamina-associated polypeptide 2 and emerin.

J. Biol. Chem. 275, 4840-4807.

Lin, F., Morrison, J. M., Wu, W., and Worman, H. J. (2005). MAN1, an integral protein of the inner nuclear membrane, binds Smad2 and Smad3 and antagonizes transforming growth factor-beta signaling. Hum. Mol. Genet. 14, 437-445.

Lin, L., and Fisher, P. A. (1990). Immunoaffinity purification and functional characterization of interphase and meiotic Drosophila nuclear lamin isoforms. J. Biol. Chem. 265, 12596-12601.

Liu, J., Lee, K. K., Segura-Totten, M., Neufeld, E., Wilson, K. L., and Gruenbaum. Y. (2003). MAN1 and emerin have overlapping function(s) essential for chromosome segregation and cell division in Caenorhabditis elegans. Proc. Natl. Acad. Sci. U. S. A. 100, 4598-4603.

Lloyd, D. J., Trembath, R. C., and Shackleton, S. (2002). A novel interaction between lamin A and SREBP1: implications for partial lipodystrophy and other laminopathies.

Hum. Mol. Genet. 11, 769-777.

Luderus, M. E., de Graaf, A., Mattia, E., den Blaauwen, J. L., Grande, M. A., de Jong, L., and van Driel, R. (1992). Binding of matrix attachment regions to lamin B1.

Cell 70, 949-959.

Luderus, M. E., den Blaauwen, J. L., de Smit, O. J., Compton, D. A., and van Driel, R. (1994). Binding of matrix attachment regions to lamin polymers involves single-stranded regions and the minor groove. Mol. Cell. Biol. 14, 6297-6305.

Machiels, B. M., Zorenc, A. H., Endert, J. M., Kuijpers, H. J., van Eys, G.J., Ramaekers, F. C., and Broers, J.L. (1996). An alternative splicing product of the lamin A/C gene lacks exon 10. J. Biol. Chem. 271, 9249-9253.

Malone, C. J., Fixsen, W. D., Horvitz, H. R., and Han, M. (1999). UNC-84 localizes to the nuclear envelope and is required for nuclear migration and anchoring during $C$. elegans development. Development 126, 3171-3181.

Malone, C. J., Misner, L., Le Bot, N., Tsai, M. C., Campbell, J. M., Ahringer, J., and White, J. G. (2003). The C. elegans hook protein, ZYG-12, mediates the essential attachment between the centrosome and nucleus. Cell 115, 825-836.

Mancini, M. A., Shan, B., Nickerson, J. A., Penman, S., and Lee, W. H. (1994). The retinoblastoma gene product is a cell cycle-dependent, nuclear matrix-associated protein. Proc. Natl. Acad. Sci. U. S. A. 91, 418-422.

Manilal, S., Nguyen, T. M., Sewry, C. A., and Morris, G. E. (1996). The Emery-Dreifuss muscular dystrophy protein, emerin, is a nuclear membrane protein. Hum. Mol. Genet. 5, 801-808.

Markiewicz, E., Venables, R., Alvarez-Reyes, M., Quinlan, R., Dorobek, M., Hausmanowa-Petrucewicz, I., and Hutchison, C. (2002). Increased solubility of lamins and redistribution of lamin C in X-linked Emery-Dreifuss muscular dystrophy fibroblasts.

J. Struct. Biol. 140, 241-253.

Markiewicz, E., Ledran, M., and Hutchison, C. J. (2005). Remodelling of the nuclear lamina and nucleoskeleton is required for skeletal muscle differentiation in vitro. J. Cell Sci. 118, 409-420.

Marshall, W. F., Straight, A., Marko, J. F., Swedlow, J., Dernburg, A., Belmont, A., Murray, A. W., Agard, D. A., and Sedat, J. W. (1997). Interphase chromosomes undergo constrained diffusional motion in living cells. Curr. Biol. 7, 930-939. 
Maske, C. P., Hollinshead, M. S., Higbee, N. C., Bergo, M. O., Young, S. G., and Vaux, D. J. (2003). A carboxylterminal interaction of lamin B1 is dependent on the CAAX endoprotease Rce1 and carboxymethylation. J. Cell Biol. $162,1223-1232$.

McKeon, F. D., Kirschner, M. W., and Caput D. (1986). Homologies in both primary and secondary structure between nuclear envelope and intermediate filament proteins.

Nature 319, 463-468.

Meier, J., Campbell, K. H., Ford, C. C., Stick, R., and Hutchison, C. J. (1991). The role of lamin LIII in nuclear assembly and DNA replication, in cell-free extracts of Xenopus eggs. J. Cell Sci. 98, 271-279.

Miller, R. G., Layzer, R. B., Mellenthin, M. A., Golabi, M., Francoz, R. A., and Mall, J. C. (1985). Emery-Dreifuss muscular dystrophy with autosomal dominant transmission. Neurology 35, 1230-1233.

Moir, R. D., Spann, T. P., Herrmann, H., and Goldman, R. D. (2000a). Disruption of nuclear lamin organization blocks the elongation phase of DNA replication. J. Cell Biol. 149, 1179-1192.

Moir, R. D., Yoon, M., Khuon, S., and Goldman, R. D. (2000b). Nuclear lamins A and B1: different pathways of assembly during nuclear envelope formation in living cells.

J. Cell Biol. 151, 1155-1168.

Mounkes, L. C., Kozlov, S., Hernandez, L., Sullivan, T., and Stewart, C. L. (2003). A progeroid syndrome in mice is caused by defects in A-type lamins. Nature 423, 298-301.

Muchir, A., Bonne, G., van der Kooi, A. J., van Meegen, M., Baas, F., Bolhuis, P. A., de Visser, M., and Schwartz, K. (2000). Identification of mutations in the gene encoding lamins A/C in autosomal dominant limb girdle muscular dystrophy with atrioventricular conduction disturbances (LGMD1B). Hum. Mol. Genet. 9, 1453-1459.

Muchir, A., van Engelen, B. G., Lammens, M., Mislow, J. M., McNally, E., Schwartz, K., and Bonne, G. (2003). Nuclear envelope alterations in fibroblasts from LGMD1B patients carrying nonsense Y259X heterozygous or homozygous mutation in lamin A/C gene. Exp. Cell Res. 291, 352-362.

Muchir, A., Medioni, J., Laluc, M., Massart, C., Arimura, T., van der Kooi, A. J., Desguerre, I., Mayer, M., Ferrer, X., Briault, S., Hirano, M., Worman, H. J., Mallet, A., Wehnert, M., Schwartz, K., and Bonne, G. (2004). Nuclear envelope alterations in fibroblasts from patients with muscular dystrophy, cardiomyopathy, and partial lipodystrophy carrying lamin A/C gene mutations. Muscle Nerve 30, 444-450.

Nagano, A., Koga, R., Ogawa, M., Kurano, Y., Kawada, J., Okada, R., Hayashi, Y. K., Tsukahara, T., and Arahata, K. (1996). Emerin deficiency at the nuclear membrane in patients with Emery-Dreifuss muscular dystrophy. Nat. Genet. 12, 254-259.

Naismith, T. V., Heuser, J. E., Breakefield, X. O., and Hanson, P. I. (2004). TorsinA in the nuclear envelope. Proc. Natl. Acad. Sci. U. S. A. 101, 7612-7617.

Navarro, C. L., De Sandre-Giovannoli, A., Bernard, R., Boccaccio, I., Boyer, A., Genevieve, D., Hadj-Rabia, S., Gaudy-Marqueste, C., Smitt, H. S., Vabres, P., Faivre, L., Verloes, A., Van Essen, T., Flori, E., Hennekam, R., Beemer, F. A., Laurent, N., Le Merrer, M., Cau, P., and Levy, N. (2004). Lamin A and ZMPSTE24 (FACE-1) defects cause nuclear disorganization and identify restrictive dermopathy as a lethal neonatal laminopathy. Hum. Mol. Genet. 13, 2493-2503.

Niebroj-Dobosz, I., Fidzianska, A., and Hausmanowa-Petrusewicz, I. (2003). Expression of emerin and lamins in muscle of patients with different forms of Emery-Dreifuss muscular dystrophy. Acta Myol. 22, 52-57.

Nikolova, V., Leimena, C., McMahon, A. C., Tan, J. C., Chandar, S., Jogia, D., Kesteven, S. H., Michalicek, J., Otway, R., Verheyen, F., Rainer, S., Stewart, C. L., Martin, D., Feneley, M. P., and Fatkin, D. (2004). Defects in nuclear structure and function promote dilated cardiomyopathy in lamin A/C-deficient mice. J. Clin. Invest. 113, 357-369. 
Nili, E., Cojocaru, G. S., Kalma, Y., Ginsberg, D., Copeland, N. G., Gilbert, D. J., Jenkins, N. A., Berger, R., Shaklai, S., Amariglio, N., Brok-Simoni, F., Simon, A. J., and Rechavi, G. (2001). Nuclear membrane protein LAP2beta mediates transcriptional repression alone and together with its binding partner GCL (germ-cell-less).

J. Cell Sci. 114, 3297-3307.

Novelli, G., Muchir, A., Sangiuolo, F., Helbling-Leclerc, A., D'Apice, M. R., Massart, C., Capon, F., Sbraccia, P., Federici, M., Lauro, R., Tudisco, C., Pallotta, R., Scarano, G., Dallapiccola, B., Merlini, L., and Bonne, G. (2002). Mandibuloacral dysplasia is caused by a mutation in LMNA-encoding lamin A/C. Am. J. Hum. Genet. 71, 426-431.

Mercuri, E., Poppe, M., Quinlivan, R., Messina, S., Kinali, M., Demay, L., Bourke, J., Richard, P., Sewry, C., Pike, M., Bonne, G., Muntoni, F., and Bushby, K. (2004). Extreme variability of phenotype in patients with an identical missense mutation in the lamin A/C gene: from congenital onset with severe phenotype to milder classic EmeryDreifuss variant. Arch. Neurol. 61, 690-694.

Novelli, G., Muchir, A., Sangiuolo, F., Helbling-Leclerc, A., D'Apice, M. R., Massart, C., Capon, F., Sbraccia, P., Federici, M., Lauro, R., Tudisco, C., Pallotta, R., Scarano, G., Dallapiccola, B., Merlini, L., and Bonne, G. (2002). Mandibuloacral dysplasia is caused by a mutation in LMNA-encoding lamin A/C. Am. J. Hum. Genet. 71, 426-431.

Ohba, T., Schirmer, E. C., Nishimoto, T., and Gerace, L. (2004). Energy- and temperature-dependent transport of integral proteins to the inner nuclear membrane via the nuclear pore. J. Cell Biol. 167, 1051-1062.

Osada, S., Ohmori, S. Y., and Taira, M. (2003). XMAN1, an inner nuclear membrane protein, antagonizes BMP signaling by interacting with Smad1 in Xenopus embryos.

Development 130, 1783-1794

Östlund, C., Ellenberg, J., Hallberg, E., Lippincott-Schwartz, J., and Worman, H. J. (1999). Intracellular trafficking of emerin, the Emery-Dreifuss muscular dystrophy protein. J. Cell Sci. 112, 1709-1719.

Östlund, C., Bonne, G., Schwart,z K., and Worman, H. J. (2001). Properties of lamin A mutants found in EmeryDreifuss muscular dystrophy, cardiomyopathy and Dunnigan-type partial lipodystrophy. J. Cell Sci. 114, 4435-4445.

Ozaki, T., Saijo, M., Murakami, K., Enomoto, H., Taya, Y., and Sakiyama, S. (1994). Complex formation between lamin A and the retinoblastoma gene product: identification of the domain on lamin A required for its interaction. Oncogene 9, 2649-2653.

Ozelius, L. J., Hewett, J., Kramer, P., Bressman, S. B., Shalish, C., de Leon, D., Rutter, M., Risch, N., Brin, M. F., Markova, E. D., Limborska, S. A., Ivanova-Smolenskaya, I. A., McCormick, M. K., Fahn, S., Buckler, A. J., Gusella, J. F., and Breakefield, X. O. (1997a). Fine localization of the torsion dystonia gene (DYT1) on human chromosome 9q34: YAC map and linkage disequilibrium. Genome Res. 7, 483-494.

Ozelius, L. J., Hewett, J. W., Page, C. E., Bressman, S. B., Kramer, P. L., Shalish, C., de Leon, D., Brin, M. F., Raymond, D., Corey, D. P., Fahn, S., Risch, N. J., Buckler, A. J., Gusella, J. F., and Breakefield, X. O. (1997b). The early-onset torsion dystonia gene (DYT1) encodes an ATP-binding protein. Nat. Genet. 17, 40-48.

Pallotta, R., and Morgese, G. (1984). Mandibuloacral dysplasia: a rare progeroid syndrome. Two brothers confirm autosomal recessive inheritance. Clin. Genet. 26, 133-138.

Pan, D., Estevez-Salmeron, L. D., Stroschein, S. L., Zhu, X., He, J., Zhou, S., and Luo, K. (2005). The integral inner nuclear membrane protein MAN1 physically interacts with the R-Smad proteins to repress signaling by the TGFbeta superfamily of cytokines.

J. Biol. Chem. In press.

Patterson, K., Molofsky, A. B., Robinson, C., Acosta, S., Cater, C., and Fischer, J. A. (2004). The functions of Klarsicht and nuclear lamin in developmentally regulated nuclear migrations of photoreceptor cells in the Drosophila eye. Mol. Biol. Cell 15, 600-610.

Paulin-Levasseur, M., Blake, D. L., Julien, M., and Rouleau, L. (1996). The MAN antigens are non-lamin constituents of the nuclear lamina in vertebrate cells. Chromosoma 104, 367-379. 
Pelger, K. (1928). Demonstratie van een paar zeldzaam voorkomende typen van bloedlichaampjes en bespreking der patienten. Ned. Tijdschr. Geneeskd. 72, 1178.

Pendás, A. M., Zhou, Z., Cadinanos, J., Freije, J. M., Wang, J., Hultenby, K., Astudillo, A., Wernerson, A., Rodriguez, F., Tryggvason, K., and Lopez-Otin, C. (2002). Defective prelamin A processing and muscular and adipocyte alterations in Zmpste24 metalloproteinase-deficient mice. Nat. Genet. 31, 94-99.

Peter, M., Nakagawa, J., Doree, M., Labbe, J. C., and Nigg, E. A. 1990. In vitro disassembly of the nuclear lamina and $\mathrm{M}$ phase-specific phosphorylation of lamins by cdc2 kinase. Cell 61, 591-602.

Peters, J. M., Barnes, R., Bennett, L., Gitomer, W. M., Bowcock, A. M., and Garg, A. (1998). Localization of the gene for familial partial lipodystrophy (Dunnigan variety) to chromosome 1q21-22. Nat. Genet. 18, $292-295$.

Plasilova, M., Chattopadhyay, C., Pal, P., Schaub, N. A., Buechner, S. A., Mueller, H., Miny, P., Ghosh, A., and Heinimann, K. (2004). Homozygous missense mutation in the lamin A/C gene causes autosomal recessive Hutchinson-Gilford progeria syndrome. J. Med. Genet. 41, 609-614.

Prufert, K., Vogel, A., and Krohne, G. (2004). The lamin CxxM motif promotes nuclear membrane growth. J. Cell Sci. 117, 6105-6116.

Rabut, G., Lenart, P. and Ellenberg, J. (2004). Dynamics of nuclear pore complex organization through the cell cycle. Curr. Opin. Cell Biol. 16, 314-321.

Raffaele Di Barletta, M., Ricci, E., Galluzzi, G., Tonali, P., Mora, M., Morandi, L., Romorini, A., Voit, T., Orstavik, K. H., Merlini, L., Trevisan, C., Biancalana, V., Housmanowa-Petrusewicz, I., Bione, S., Ricotti, R., Schwartz, K., Bonne, G., and Toniolo, D. (2000). Different mutations in the LMNA gene cause autosomal dominant and autosomal recessive Emery-Dreifuss muscular dystrophy. Am. J. Hum. Genet. 66, 1407-1412.

Raharjo, W. H., Enarson, P., Sullivan, T., Stewart, C. L., and Burke, B. (2001). Nuclear envelope defects associated with $L M N A$ mutations cause dilated cardiomyopathy and Emery-Dreifuss muscular dystrophy. J. Cell Sci. 114, 44474457.

Ralle, T., Grund, C., Franke, W. W., and Stick, R. (2004). Intranuclear membrane structure formations by CaaXcontaining nuclear proteins. J. Cell Sci. 117, 6095-6104.

Raju, G. P., Dimova, N., Klein, P. S., and Huang, H. C. (2003). SANE, a novel LEM domain protein, regulates bone morphogenetic protein signaling through interaction with Smad1. J. Biol. Chem. 278, 428-437.

Reichart, B., Klafke, R., Dreger, C., Kruger, E., Motsch, I., Ewald, A., Schafer, J., Reichmann, H., Muller, C. R., and Dabauvalle, M. C. (2004). Expression and localization of nuclear proteins in autosomal-dominant Emery-Dreifuss muscular dystrophy with LMNA R377H mutation. BMC Cell Biol. 5, 12.

Reitman, M. L., Arioglu, E., Gavrilova, O., and Taylor, S. I. (2000). Lipoatrophy revisited. Trends Endocrinol. Metab. 11, 410-416.

Riemer, D., Dodemont, H., and Weber, K. (1993). A nuclear lamin of the nematode Caenorhabditis elegans with unusual structural features; cDNA cloning and gene organization. Eur. J. Cell Biol. 62, 214-223.

Riemer, D., and Weber, K. (1994). The organization of the gene for Drosophila lamin C: limited homology with vertebrate lamin genes and lack of homology versus the Drosophila lamin Dmo gene. Eur. J. Cell Biol. 63, $299-306$.

Rober, R. A., Weber, K., and Osborn, M. (1989). Differential timing of nuclear lamin A/C expression in the various organs of the mouse embryo and the young animal: a developmental study. Development 105, 365-378.

Rober, R. A., Sauter, H., Weber, K., and Osborn, M. (1990). Cells of the cellular immune and hemopoietic system of the mouse lack lamins A/C: distinction versus other somatic cells. J. Cell Sci. 95, 587-598.

Rout, M. P., Aitchison, J. D., Suprapto, A., Hjertaas, K., Zhao, Y., and Chai,t B. T. (2000) The yeast nuclear pore complex: composition, architecture, and transport mechanism. J. Cell Biol. 148, 635-651. 
Rowland, L. P., Fetell, M., Olarte, M., Hays, A., Singh, N., and Wanat, F. E. (1979). Emery-Dreifuss muscular dystrophy. Ann. Neurol. 5, 111-117.

Rozencwaig, R., Wilson, M. R., and McFarland, G.B., Jr. (1997). Melorheostosis. Am. J. Orthop. 26, 83-89.

Sabatelli, P., Lattanzi, G., Ognibene, A., Columbaro, M., Capanni, C., Merlini, L., Maraldi, N. M., and Squarzoni, S. (2001). Nuclear alterations in autosomal-dominant Emery-Dreifuss muscular dystrophy. Muscle Nerve 24, $826-829$.

Saifi, G. M., Szigeti, K., Snipes, G. J., Garcia, C. A., and Lupski, J. R. (2003). Molecular mechanisms, diagnosis, and rational approaches to management of and therapy for Charcot-Marie-Tooth disease and related peripheral neuropathies. J. Investig. Med. 51, 261-283.

Sakaki, M., Koike, H., Takahashi, N., Sasagawa, N., Tomioka, S., Arahata, K., and Ishiura, S. (2001). Interaction between emerin and nuclear lamins. J. Biochem. 129, 321-327.

Salina, D., Bodoor, K., Eckley, D. M., Schroer, T. A., Rattner, J. B., and Burke, B. (2002). Cytoplasmic dynein as a facilitator of nuclear envelope breakdown. Cell 108, 97-107.

Sanna, T., Dello Russo, A., Toniolo, D., Vytopil, M., Pelargonio, G., De Martino, G., Ricci, E., Silvestri, G., Giglio, V., Messano, L., Zachara, E., and Bellocci, F. (2003). Cardiac features of Emery-Dreifuss muscular dystrophy caused by lamin A/C gene mutations. Eur. Heart J. 24, 2227-2236.

Scaffidi, P., and Misteli, T. (2005). Reversal of the cellular phenotype in the premature aging disease HutchinsonGilford progeria syndrome. Nat. Med. In press.

Scheer, U., Kartenbeck, J., Trendelenburg, M. F., Stadler, J., and Franke, W. W. (1976). Experimental disintegration of the nuclear envelope. Evidence for pore-connecting fibrils. J. Cell Biol. 69, 1-18.

Schirmer, E. C., Florens, L., Guan, T., Yates, J. R., 3rd, and Gerace, L. (2003). Nuclear membrane proteins with potential disease links found by subtractive proteomics. Science $301,1380-1382$.

Schirmer, E. C., and Gerace, L. (2004). The stability of the nuclear lamina polymer changes with the composition of lamin subtypes according to their individual binding strengths. J. Biol. Chem. 279, 42811-42817.

Schuler, E., Lin, F., and Worman, H. J. (1994). Characterization of the human gene encoding LBR, an integral protein of the nuclear envelope inner membrane. J. Biol. Chem. 269, 11312-11317.

Sebillon, P., Bouchier, C., Bidot, L. D., Bonne, G., Ahamed, K., Charron, P., Drouin-Garraud, V., Millaire, A., Desrumeaux, G., Benaiche, A., Charniot, J. C., Schwartz, K., Villard, E., and Komajda, M. (2003). Expanding the phenotype of $L M N A$ mutations in dilated cardiomyopathy and functional consequences of these mutations. J. Med. Genet. 40, 560-567.

Shashidharan, P., Sandu, D., Potla, U., Armata, I. A., Walker, R. H., McNaught, K. S., Weisz, D., Sreenath, T., Brin, M. F., and Olanow, C. W. (2005). Transgenic mouse model of early-onset DYT1 dystonia. Hum. Mol. Genet. 14, 125-133.

Shultz, L. D., Lyons, B. L., Burzenski, L. M., Gott, B., Samuels, R., Schweitzer, P. A., Dreger, C., Herrmann, H., Kalscheuer, V., Olins, A. L., Olins, D. E., Sperling, K., and Hoffmann, K. (2003). Mutations at the mouse ichthyosis locus are within the lamin B receptor gene: a single gene model for human Pelger-Huët anomaly. Hum. Mol. Genet. 12, 61-69.

Senior, A., and Gerace, L. (1988). Integral membrane proteins specific to the inner nuclear membrane and associated with the nuclear lamina. J. Cell Biol. 107, 2029-2036.

Sevenants, L., Wouters, C., De Sandre-Giovannoli, A., Devlieger, H., Devriendt, K., van den Oord, J. J., Marien, K., Levy, N., and Morren, M. A. (2005). Tight skin and limited joint movements as early presentation of HutchinsonGilford progeria in a 7-week-old infant. Eur. J. Pediatr. In press. 
Sewry, C. A. (2000). Immunocytochemical analysis of human muscular dystrophy.

Microsc. Res. Tech. 48, 142-154.

Sewry, C. A., Brown, S. C., Mercuri, E., Bonne, G., Feng, L., Camici, G., Morris, G. E., and Muntoni, F. (2001). Skeletal muscle pathology in autosomal dominant Emery-Dreifuss muscular dystrophy with lamin A/C mutations. Neuropathol. Appl. Neurobiol. 27, 281-290.

Shackleton, S., Lloyd, D. J., Jackson, S. N., Evans, R., Niermeijer, M. F., Singh, B. M., Schmidt, H., Brabant, G., Kumar, S., Durrington, P. N., Gregory, S., O'Rahilly, S., and Trembath, R. C. (2000). LMNA, encoding lamin A/C, is mutated in partial lipodystrophy. Nat. Genet. 24, 153-156.

Shen, J. J. Brown, C. A., Lupski, J. R., and Potocki, L. (2003). Mandibuloacral dysplasia caused by homozygosity for the R527H mutation in lamin A/C. J. Med. Genet. 40, 854-857.

Silve, S., Dupuy, P. H., Ferrara, P., and Loison, G. (1998). Human lamin B receptor exhibits sterol C14-reductase activity in Saccharomyces cerevisiae. Biochim. Biophys Acta. 1392, 233-244.

Simha,V., and Garg, A. (2002). Body fat distribution and metabolic derangements in patients with familial partial lipodystrophy associated with mandibuloacral dysplasia.

J. Clin. Endocrinol. Metab. 87, 776-785.

Simha, V. Agarwal, A. K., Oral, E. A., Fryns, J. P., and Garg, A. (2003). Genetic and phenotypic heterogeneity in patients with mandibuloacral dysplasia-associated lipodystrophy. J. Clin. Endocr. Metab. 88, 2821-2824.

Sinensky, M., Fantle, K., Trujillo, M., McLain, T., Kupfer, A., and Dalton, M. (1994). The processing pathway of prelamin A. J. Cell Sci. 107, 61-67.

Smythe, C., Jenkins, H. E., and Hutchison, C. J. (2000). Incorporation of the nuclear pore basket protein nup153 into nuclear pore structures is dependent upon lamina assembly: evidence from cell-free extracts of Xenopus eggs.

EMBO J. 19, 3918-3931.

Soullam, B., and Worman, H. J. (1993). The amino-terminal domain of the lamin B receptor is a nuclear envelope targeting signal. J. Cell Biol. 120, 1093-1100.

Soullam, B., and Worman, H. J. (1995). Signals and structural features involved in integral membrane protein targeting to the inner nuclear membrane. J. Cell Biol. 130, 15-27.

Spann, T. P., Moir, R. D., Goldman, A. E., Stick, R., and Goldman, R. D. (1997). Disruption of nuclear lamin organization alters the distribution of replication factors and inhibits DNA synthesis. J. Cell Biol. 136, 1201-1212.

Spann, T. P., Goldman, A. E., Wang, C., Huang, S., and Goldman, R. D. (2002). Alteration of nuclear lamin organization inhibits RNA polymerase II-dependent transcription. J. Cell Biol. 156, 603-608.

Speckman, R. A., Garg, A., Du, F., Bennett, L., Veile, R., Arioglu, E., Taylor, S. I., Lovett, M., and Bowcock, A. M. (2000). Mutational and haplotype analyses of families with familial partial lipodystrophy (Dunnigan variety) reveal recurrent missense mutations in the globular C-terminal domain of lamin A/C. Am. J. Hum. Genet. 66, 1192-1198.

Starr, D. A., and Han, M. (2002). Role of ANC-1 in tethering nuclei to the actin cytoskeleton. Science 298, $406-409$.

Starr, D. A., and Han, M. (2003). ANChors away: an actin based mechanism of nuclear positioning. J. Cell Sci. 116, 211-216.

Stewart, C., and Burke, B. (1987). Teratocarcinoma stem cells and early mouse embryos contain only a single major lamin polypeptide closely resembling lamin B.

Cell 51, 383-392.

Stick, R. (1988). cDNA cloning of the developmentally regulated lamin LIII of Xenopus laevis. EMBO J. 7, 31893197. 
Stick, R. (1992). The gene structure of Xenopus nuclear lamin A: a model for the evolution of A-type from B-type lamins by exon shuffling. Chromosoma 101, 566-574.

Stick, R. (1994). The gene structure of B-type nuclear lamins of Xenopus laevis: implications for the evolution of the vertebrate lamin family. Chromosome Res. 2, 376-82.

Stierlé, V., Couprie, J., Östlund, C., Krimm, I., Zinn-Justin, S., Hossenlopp, P., Worman, H. J., Courvalin, J. C., and Duband-Goulet, I. (2003). The carboxyl-terminal region common to lamins A and C contains a DNA binding domain. Biochemistry 42, 4819-4828.

Straub, V., and Campbell, K. P. (1997). Muscular dystrophies and the dystrophin-glycoprotein complex. Curr. Opin. Neurol. 10, 168-175.

Sullivan, T., Escalante-Alcalde, D., Bhatt, H., Anver, M., Bhat, N., Nagashima, K., Stewart, C. L., and Burke, B. (1999). Loss of A-type lamin expression compromises nuclear envelope integrity leading to muscular dystrophy. J. Cell Biol. 147, 913-920.

Suntharalingam, M., and Wente, S. R. (2003). Peering through the pore: nuclear pore complex structure, assembly, and function. Dev. Cell 4, 775-789.

Taniura, H., Glass, C., and Gerace, L. (1995). A chromatin binding site in the tail domain of nuclear lamins that interacts with core histones. J. Cell Biol. 131, 33-44.

Taylor, M. R., Fain, P. R., Sinagra, G., Robinson, M. L., Robertson, A. D., Carniel, E., Di Lenarda, A., Bohlmeyer, T. J., Ferguson, D. A., Brodsky, G. L., Boucek, M. M., Lascor, J., Moss, A. C., Li, W. L., Stetler, G. L., Muntoni, F., Bristow, M. R., Mestroni, L., and Familial Dilated Cardiomyopathy Registry Research Group. (2003). Natural history of dilated cardiomyopathy due to lamin A/C gene mutations. J. Am. Coll. Cardiol. 41, 771-780.

Tazir, M., Azzedine, H., Assami, S., Sindou, P., Nouioua, S., Zemmouri, R., Hamadouche, T., Chaouch, M., Feingold, J., Vallat, J. M., Leguern, E., and Grid, D. (2004). Phenotypic variability in autosomal recessive axonal CharcotMarie-Tooth disease due to the R298C mutation in lamin A/C. Brain 127, 154-163.

Tsuchiya, Y., Hase, A., Ogawa, M., Yorifuji, H., and Arahata, K. (1999). Distinct regions specify the nuclear membrane targeting of emerin, the responsible protein for Emery-Dreifuss muscular dystrophy. Eur. J. Biochem. 259, 859-865.

Tsukahara, T., Tsujino, S., and Arahata, K. (2002). CDNA microarray analysis of gene expression in fibroblasts of patients with X-linked Emery-Dreifuss muscular dystrophy.

Muscle Nerve 25, 898-901.

van Berlo, J. H., de Voogt, W. G., van der Kooi, A. J., van Tintelen, J. P., Bonne, G., Yaou, R. B., Duboc, D., Rossenbacker, T., Heidbuchel, H., de Visser, M., Crijns, H. J., and Pinto, Y. M. (2005). Meta-analysis of clinical characteristics of 299 carriers of $L M N A$ gene mutations: do lamin $\mathrm{A} / \mathrm{C}$ mutations portend a high risk of sudden death? J. Mol. Med. 83, 79-83.

van Engelen, B. G., Muchir, A., Hutchison, C. J., van der Kooi, A. J., Bonne, G., and Lammens, M. (2005). The lethal phenotype of a homozygous nonsense mutation in the lamin A/C gene. Neurology 64, 374-376.

Vantyghem, M. C., Pigny, P., Maurage, C. A., Rouaix-Emery, N., Stojkovic, T., Cuisset, J. M., Millaire, A., Lascols, O., Vermersch, P., Wemeau, J. L., Capeau, J., and Vigouroux, C. (2004). Patients with familial partial lipodystrophy of the Dunnigan type due to a LMNA R482W mutation show muscular and cardiac abnormalities. J. Clin. Endocrinol. Metab. 89, 5337-5346.

Vecerova, J., Koberna, K., Malinsky, J., Soutoglou, E., Sullivan, T., Stewart, C. L., Raska, I., and Misteli, T. (2004). Formation of nuclear splicing factor compartments is independent of lamins A/C. Mol. Biol Cell 15, 4904-4910.

Vergnes, L., Peterfy, M., Bergo, M. O., Young, S. G., and Reue, K. (2004). Lamin B1 is required for mouse development and nuclear integrity. Proc. Natl. Acad. Sci. U. S. A. 101, 10428-10433. 
Vigouroux, C., Magre, J., Vantyghem, M. C., Bourut, C., Lascols, O., Shackleton, S., Lloyd, D. J., Guerci, B., Padova, G., Valensi, P., Grimaldi, A., Piquemal, R., Touraine, P., Trembath, R. C., and Capeau, J. (2000). Lamin A/C gene: sex-determined expression of mutations in Dunnigan-type familial partial lipodystrophy and absence of coding mutations in congenital and acquired generalized lipoatrophy. Diabetes 49, 1958-1962.

Vigouroux, C., Auclair, M., Dubosclard, E., Pouchelet, M., Capeau. J., Courvalin, J. C., and Buendia, B. (2001). Nuclear envelope disorganization in fibroblasts from lipodystrophic patients with heterozygous R482Q/W mutations in the lamin $\mathrm{A} / \mathrm{C}$ gene.

J. Cell Sci. 114, 4459-4468.

Walter, M. C., Witt, T. N., Weigel, B. S., Reilich, P., Richard, P., Pongratz, D., Bonne, G., Wehnert, M. S., and Lochmuller, H. (2005). Deletion of the LMNA initiator codon leading to a neurogenic variant of autosomal dominant Emery-Dreifuss muscular dystrophy. Neuromuscul. Disord. 15, 40-44.

Ward, G. E., and Kirschner, M. W. (1990). Identification of cell cycle-regulated phosphorylation sites on nuclear lamin C. Cell 61, 561-577.

Wagner, N., Weber, D., Seitz, S., and Krohne, G. (2004). The lamin B receptor of Drosophila melanogaster. J. Cell Sci. 117, 2015-2028.

Waterham, H. R., Koster, J., Mooyer, P., Noort, G. G., Kelley, R. I., Wilcox, W. R., Wanders, R. J., Hennekam, R. C., and Oosterwijk, J. C. (2003). Autosomal recessive HEM/Greenberg skeletal dysplasia is caused by 3 betahydroxysterol delta 14-reductase deficiency due to mutations in the lamin B receptor gene. Am. J. Hum. Genet. 72, 1013-1017.

Weber, K., Plessmann, U., and Traub, P. (1989). Maturation of nuclear lamin A involves a specific carboxy-terminal trimming, which removes the polyisoprenylation site from the precursor; implications for the structure of the nuclear lamina. FEBS Lett. 257, 411-414.

Wildermuth, S., Spranger, S., Spranger, M., Raue, F., and Meinck, H. M.(1996). Köbberling-Dunnigan syndrome: a rare cause of generalized muscular hypertrophy.

Muscle Nerve 19, 843-847.

Wilkinson, F. L., Holaska, J. M., Zhang, Z., Sharma, A., Manilal, S., Holt, I., Stamm, S., Wilson, K. L., and Morris, G. E. (2003). Emerin interacts in vitro with the splicing-associated factor, YT521-B. Eur. J. Biochem. 270, 2459-2466.

Wilson, K. L., Zastrow, M. S., and Lee, K. K. (2001). Lamins and disease: insights into nuclear infrastructure. Cell 104, 647-650.

Wolda, S. L., and Glomset, J. A. (1988). Evidence for modification of lamin B by a product of mevalonic acid. J. Biol. Chem. 263, 5997-6000.

Wolff, N., Gilquin, B., Courchay, K., Callebaut, I., Worman, H. J., and Zinn-Justin, S. (2001). Structural analysis of emerin, an inner nuclear membrane protein mutated in X-linked Emery-Dreifuss muscular dystrophy. FEBS Lett. $501,171-176$.

Worman, H. J., and Courvalin, J. C. (2000). The inner nuclear membrane. J. Membr. Biol. 177, 1-11.

Worman, H. J., and Courvalin, J. C. (2002). The nuclear lamina and inherited disease.

Trends Cell Biol. 12, 591-598.

Worman, H. J., and Courvalin, J. C. (2004). How do mutations in lamins A and C cause disease? J. Clin. Invest. 113, 349-351.

Worman, H. J., Lazaridis, I., and Georgatos, S. D. (1988). Nuclear lamina heterogeneity in mammalian cells. Differential expression of the major lamins and variations in lamin B phosphorylation. J. Biol. Chem. 263, 1213512141.

Worman, H. J., Yuan, J., Blobel, G., and Georgatos, S. D. (1988). A lamin B receptor in the nuclear envelope. Proc. Natl. Acad. Sci. U. S. A. 85, 8531-8534. 
Worman, H. J., Evans, C. D., and Blobel, G. (1990). The lamin B receptor of the nuclear envelope inner membrane: a polytopic protein with eight potential transmembrane domains. J. Cell Biol. 111, 1535-1542.

Wozniak, R. W., Bartnik, E., and Blobel G. (1989). Primary structure analysis of an integral membrane glycoprotein of the nuclear pore. J. Cell Biol. 108, 2083-2092.

Wozniak, R. W., Blobel, G., and Rout, M. P. (1994). POM152 is an integral protein of the pore membrane domain of the yeast nuclear envelope. J. Cell Biol. 125, 31-42.

Wu, W., Lin, F., and Worman, H. J. (2002). Intracellular trafficking of MAN1, an integral protein of the nuclear envelope inner membrane. J. Cell Sci. 115, 1361-1371.

Wydner, K. L., McNeil, J. A., Lin, F., Worman, H. J., and Lawrence, J. B. (1996). Chromosomal assignment of human nuclear envelope protein genes $L M N A, L M N B 1$, and $L B R$ by fluorescence in situ hybridization. Genomics $\mathbf{3 2}$, 474-478.

Yang, L., Guan, T., and Gerace, L. (1997). Integral membrane proteins of the nuclear envelope are dispersed throughout the endoplasmic reticulum during mitosis. J. Cell Biol. 137, 1199-1210.

Ye, Q., and Worman, H. J. (1994). Primary structure analysis and lamin B and DNA binding of human LBR, an integral protein of the nuclear envelope inner membrane. J. Biol. Chem. 269, 11306-11311.

Ye, Q., and Worman, H. J. (1995). Protein-protein interactions between human nuclear lamins expressed in yeast. Exp. Cell Res. 219, 292-298.

Ye, Q., and Worman, H. J. (1996). Interaction between an integral protein of the nuclear envelope inner membrane and human chromodomain proteins homologous to Drosophila HP1. J. Biol. Chem. 271, 14653-14656.

Ye, Q., Callebaut, I., Pezhman, A., Courvalin, J. C., and Worman, H. J. (1997). Domain-specific interactions of human HP1-type chromodomain proteins and inner nuclear membrane protein LBR. J. Biol. Chem. 272, 1498314989.

Young, K. G., and Kothary, R. (2005). Spectrin repeat proteins in the nucleus.

Bioessays 27, 144-152.

Young, L. W., Radebaugh, J. F., Rubin, P., Sensenbrenner, J. A., Fiorelli, G., and McKusick, V. A. (1971). New syndrome manifested by mandibular hypoplasia, acroosteolysis, stiff joints and cutaneous atrophy (mandibuloacral dysplasia) in two unrelated boys. Birth Defects Orig. Artic. Ser. 7, 291-297.

Zhang, Q., Skepper, J. N., Yang, F., Davies, J. D., Hegyi, L., Roberts, R. G., Weissberg, P. L., Ellis, J. A., and Shanahan, C. M. (2001). Nesprins: a novel family of spectrin-repeat-containing proteins that localize to the nuclear membrane in multiple tissues.

J. Cell Sci. 114, 4485-4498.

Zhang, Q., Ragnauth, C. D., Skepper, J. N., Worth, N. F., Warren, D. T., Roberts, R. G., Weissberg, P. L., Ellis, J. A., and Shanahan, C. M. (2005). Nesprin-2 is a multi-isomeric protein that binds lamin and emerin at the nuclear envelope and forms a subcellular network in skeletal muscle. J. Cell Sci. 118, 673-687.

Zina, A. M., Cravario, A., and Bundino, S. (1981). Familial mandibuloacral dysplasia. Br. J. Dermatol. 105, 719-723. 


\section{Figure Legends}

Figure 1. Schematic diagram of the nuclear envelope showing the inner, pore and outer nuclear membranes, the continuous endoplasmic reticulum (ER) membrane, the nuclear lamina and a nuclear pore complex. Integral proteins of the pore membrane include POM121 and gp210, which comprise part of the pore complexes. Representative integral inner nuclear membrane proteins shown are MAN1, LBR, nurim, a SUN protein and another polypeptide with a single transmembrane segment that could represent emerin or one of the lamina-associated polypeptides (LAPs). A nesprin is shown in the outer nuclear membrane with its with its cytoplasmic calponin homology domain $(\mathrm{CH})$ and its luminal KASH domain, which can interact directly or indirectly with the luminal SUN domain of SUN1 and SUN2. Lamina is represented apposed to the inner nuclear membrane and peripheral heterochromatin, in tight contact with the nuclear pore complex (NPC). The lamina is fenestrated, allowing for the direct contact of the inner nuclear membrane and its integral proteins herein with chromatin. Note that the left side of the nuclear pore complex is not in contact with the pore membrane, representing lateral channels of approximately $10 \mathrm{~nm}$ in diameter, which allow the for diffusion of integral proteins synthesized on the rough endoplasmic reticulum membrane to the inner nuclear membrane.

Figure 2. Nuclear lamins and their genes. $L M N A$ on chromosome 1 encodes lamin $A$ and lamin $C$ (as well as a minor isoform lamin $A \Delta 10$ and a germ cell isoform lamin $C 2$, not shown). Lamins $A$ and $C$ are identical for their first 566 amino acids; lamin $C$ contains 6 unique amino acids (white rectangle) and lamin A 98 unique amino acids. LMNB1 on chromosome 5 encodes lamin B1. LMNB2 on chromosome 19 encodes lamin B2 (and a germ cell isoform lamin B3, not shown). The lamin proteins contain head and tail domains (thin lines) and alpha helical central rod domains (gray rectangles). Lamins contain a nuclear localization signal (NLS) in their tail domains. All lamins except lamin C (and C2) contain a CAAX box (CAAM) at their carboxyl-termini, which is a signal for farnesylation (squiggly line). A protease cleaves off the three terminal amino acids (double headed arrow) as part of the prenylation reaction (the cysteine is also carboxymethylated in the process). Prelamin A is also cleaved "upstream" from the prenylated cysteine (double headed arrow to the left) in a second proteolytic reaction to yield mature lamin $\mathrm{A}$.

Figure 3. Schematic diagram of prelamin A showing the nature and locations of disease-causing mutations. Thin gray rectangle at left is the head domain, thicker blue rectangles the rod domain and thin gray rectangle at right the tail domain; these sequences are common to lamins $\mathrm{A}$ and $\mathrm{C}$. The nuclear localization signal is represented by light blue. The orange striped area at the far right represents sequence absent from lamin C. Mutations that cause the striated muscle diseases EmeryDreifuss muscular dystrophy (EDMD, red), limb girdle muscular dystrophy type 1B (LGMD1B, orange) and dilated cardiomyopathy with conduction defect (DCM-CD, pink) are shown above the schematic diagram of the molecule. Mutations causing Charcot- 
Marie-Tooth disorder type 2A (CMT2A, dark red), Dunnigan-type familial partial lipodystrophy (FPLD, dark green), lipoatrophy, insulin-resistant diabetes, disseminated leukomelanodermic papules, liver steatosis, and cardiomyopathy (LILLC, light green), mandibuloacral dysplasia (MAD, purple), Hutchinson-Gilford progeria syndrome (HGPS, dark blue), Seip syndrome (Seip, light blue) and atypical Werner syndrome (AWS, lighter blue) are shown below the schematic diagram of the molecule. The R28W and R62G mutations shown for FPLD are atypical cases with cardiac disease; $90 \%$ of cases have mutations at either residue 482 or 486 . For HGPS, the classical cases have either the G608G mutation or, more rarely, the G608S mutation; the others have been reported in atypical cases.

Figure 4. Schematic diagram outlining the steps in the processing of prelamin A to lamin A. Amino acids in prelamin A encoded by part of $L M N A$ exon 11 and exon 12 are shown. See text for details. 
Figure 1

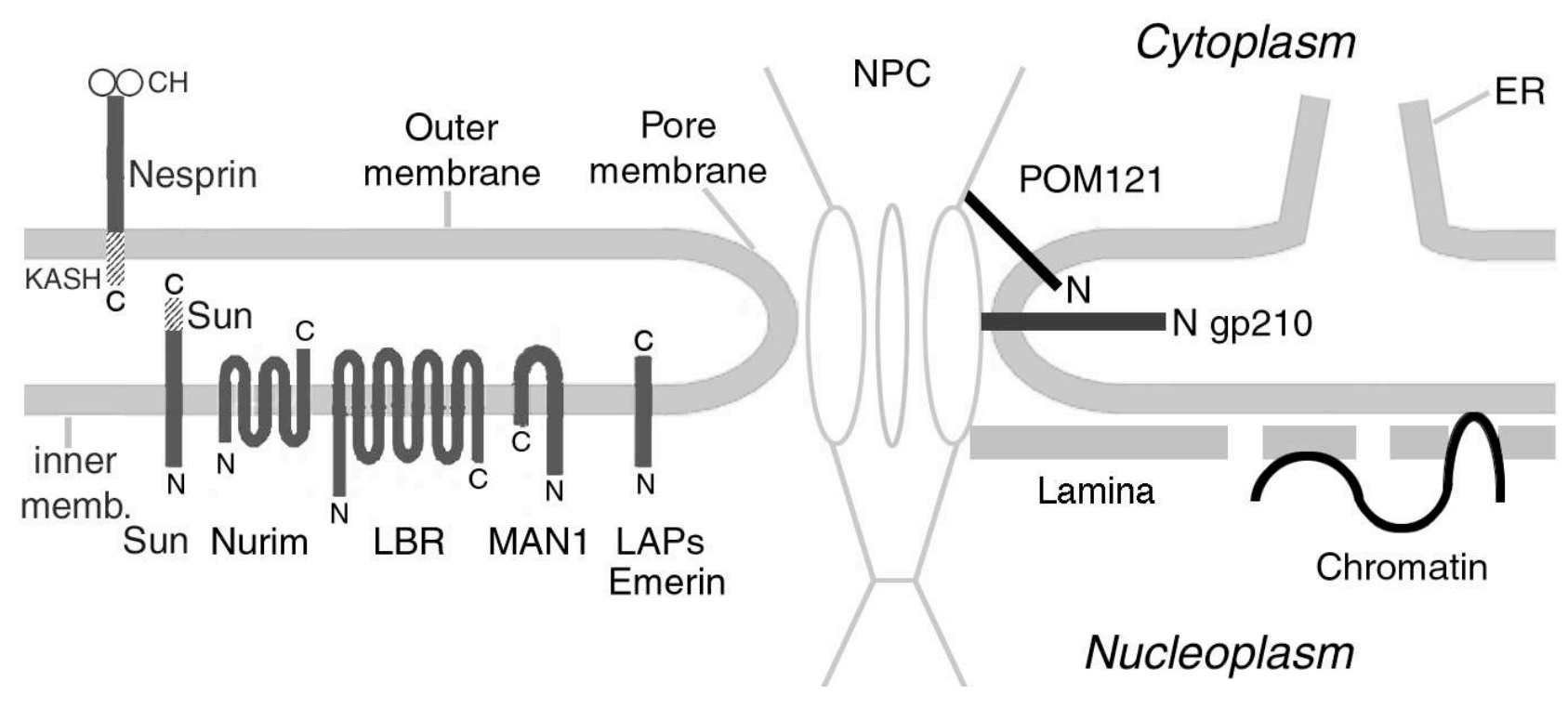


Figure 2

Chr/Genes Lamins

1 LMNA $\quad \begin{aligned} & \mathrm{A} \\ & \mathrm{C}\end{aligned}$

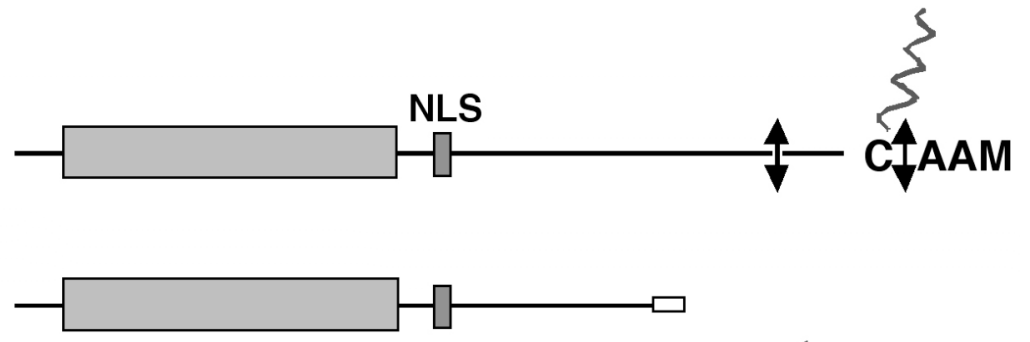

5 LMNB1

B1

19 LMNB2

B2
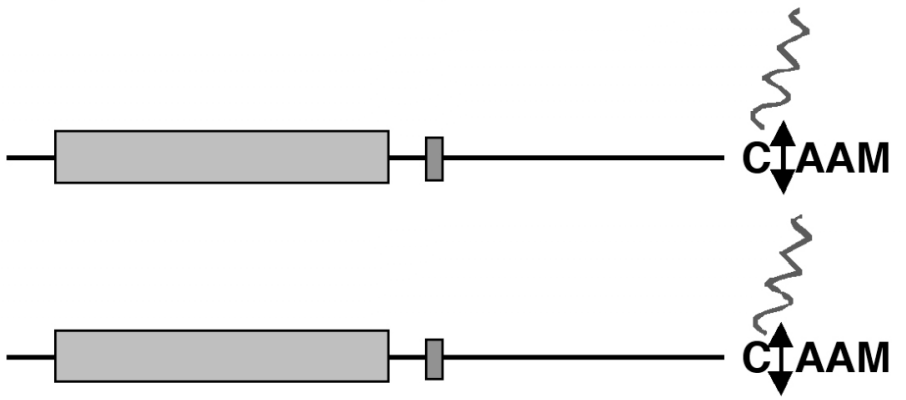

48 
Figure 3

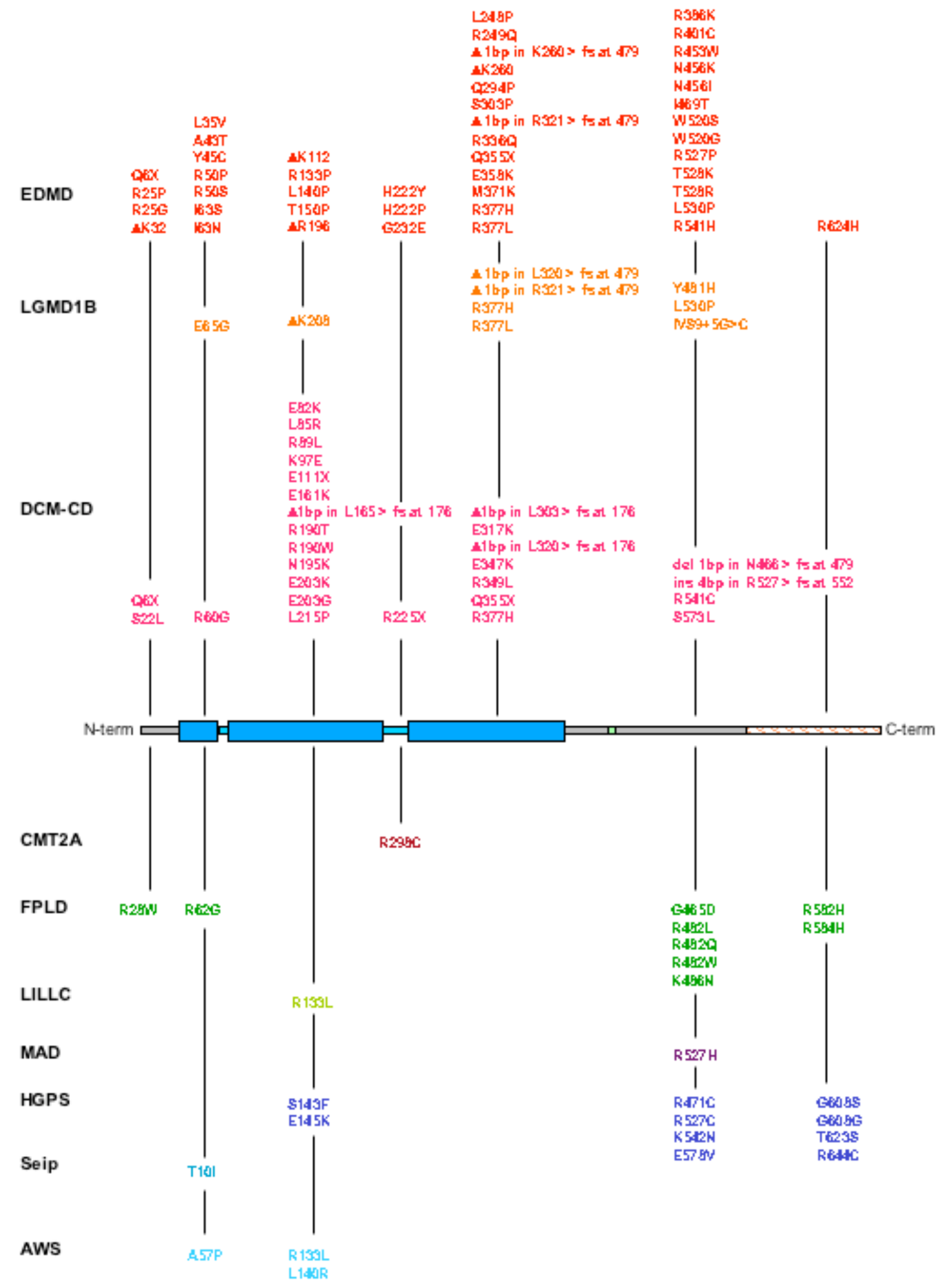


Figure 4

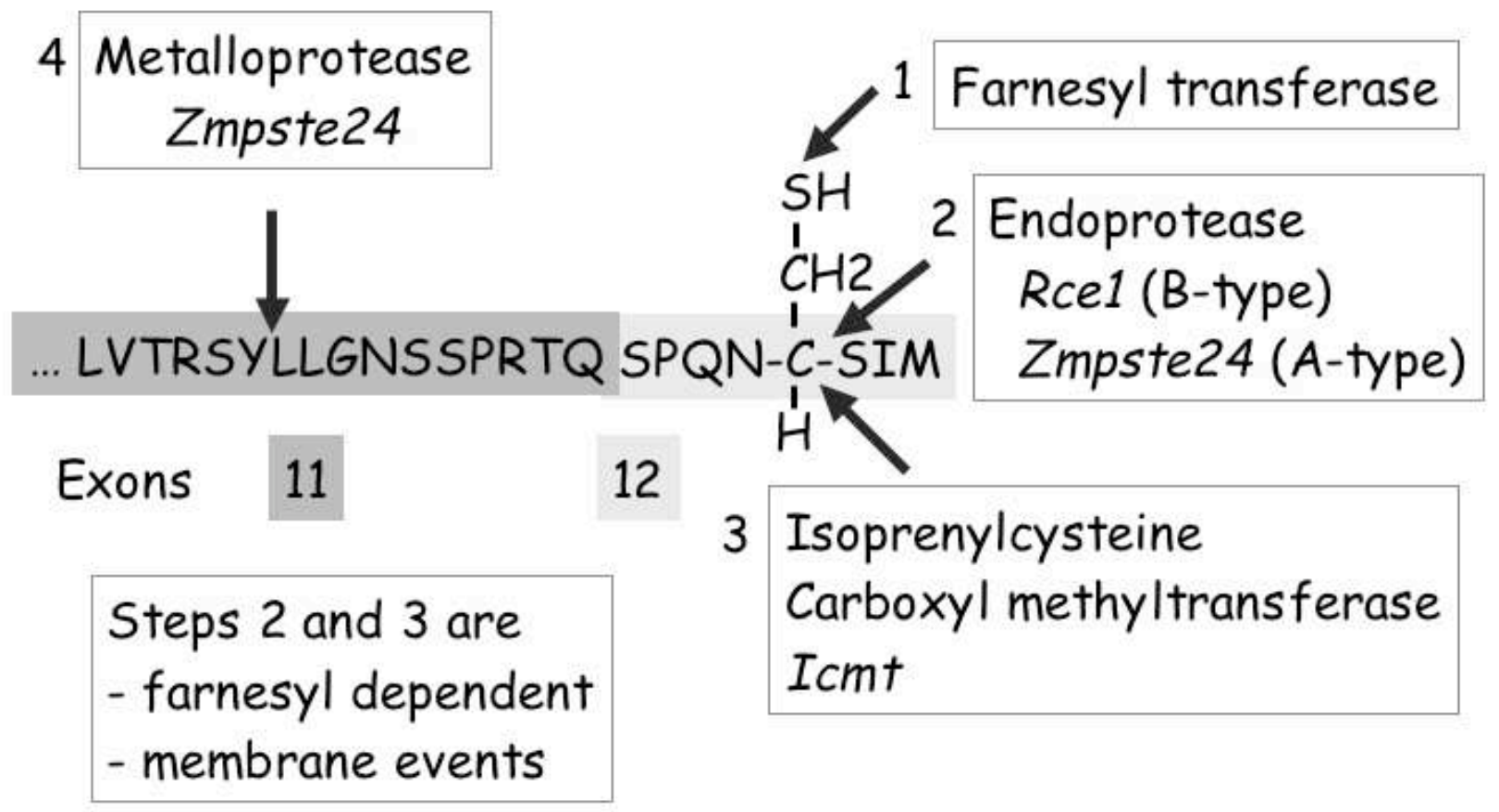

